\title{
Implications of Index Construction Methodologies for Price and Dividend Indices ${ }^{\ddagger}$
}

\author{
Georg Cejnek* and Otto Randl ${ }^{\S}$ \\ WU (Vienna University of Economics and Business)
}

May 3, 2013

\begin{abstract}
Investment products tracking the performance of equity indices have become irreplaceable in the investment community. We are the first to analyze the impact of index replacements and the choice of indexing methodologies on relative performance, using one consistent approach for price indices and dividend indices, which have recently been developed. We implement an empirical case study as well as an extensive simulation study incorporating mean reversion and momentum in the process for price-to-dividend ratios. Calibrating our model to capital market dynamics, we find that periodically rebalanced market capitalization weighted indices are outperformed by buy-and-hold portfolios and also by fundamentally weighted indices. Rebalancing affects dividend indices more adversely than price indices. We highlight sensitivities of performance dispersion between different index methodologies by varying mean reversion and momentum parameters. Mean reversion dominates momentum as driving force in our setup. We identify index size, rebalancing frequency and criteria applied to assign weights as key variables affecting the relative performance of price and dividend indices. As a consequence, choosing an index methodology can be considered as an active strategy.
\end{abstract}

Keywords: index performance; index selection and rebalancing rules; equity indices; dividend indices; fundamental indexation

EFM Classification: 330,370

JEL Codes: G10, G11, G17

\footnotetext{
${ }^{\ddagger}$ We thank Thomas Dangl, Engelbert Dockner, Alois Geyer, Christian Laux, Stefan Pichler, Guido Schaefer, Neal Stoughton and Josef Zechner for helpful discussions. Moreover, we appreciate the feedback of conference participants at the Austrian Working Group on Banking and Finance (AWG) meetings 2012 in Innsbruck and participants of the finance brown bag seminar at WU. All errors remain our own.

${ }^{*}$ Correspondence Information: WU (Vienna University of Economics and Business), Research Institute for Capital Markets; Coburgbastei 4, Top 5, 1010 Vienna, Austria; tel: +43-1-518 18 934, fax: +43-1-518 18 550, e-mail: georg.cejnek@wu.ac.at

¿Correspondence Information: WU (Vienna University of Economics and Business); Heiligenstädterstrasse 46, 1190 Vienna, Austria; tel: +43-1-313 36 5076, fax:+43-1-313 36 904691, e-mail: otto.randl@wu.ac.at
} 


\section{Introduction}

Investment products tracking the performance of equity indices, regardless whether those indices are oriented towards geographical, sector or style criteria, have become vitally important in the investment community. Popular examples are ETFs and futures contracts as well as index options providing index investors with non-linear payoffs. The importance of equity indices as underlyings for those products can be seen from the fact that index futures contracts on the Euro Stoxx 50, an important blue-chip benchmark in the Eurozone, have a capital open interest outstanding of 65 billion euros. ${ }^{1}$ In addition, the equivalent number for option contracts on the same underlying is 954 billion euros. Due to the huge investor base for these index tracking products, methodologies to construct indices and, thus, underlyings for these investment vehicles, have been scrutinized by the academic community as well as investment practitioners. Many equity indices are weighted by market capitalization, consistent with the Capital Asset Pricing Model. Nevertheless, other indexing methodologies have been proposed and implemented in practice. However, performance characteristics of different indexing methodologies depend crucially on the dynamics exhibited by the universe of stocks from which a specific equity index is composed.

A recent development is the introduction of dividend indices. Index providers apply the same construction methodology used for price or performance indices to ordinary gross dividends paid by index member companies. This is a relevant development for investors around the globe, since dividend indices have become underlyings for the rapidly growing market for dividend derivatives. ${ }^{2}$ Referring again to the Euro Stoxx 50, dividend futures referenced to the Euro Stoxx 50 dividend index have a capital open interest outstanding of 7 billion euros and the corresponding number for option contracts is 10 billion euros.

We investigate how key variables that determine an index affect the performance of indices and analyze how sensitive these effects are with respect to varying dynamics of the stock universe. We identify index size, rebalancing frequency and weighting criteria as the key drivers for performance dispersion between various index methodologies. We look into the consequences of variations of the key determinants for index performance, using a consistent methodology for both, price and dividend indices. It is interesting that price and dividend indices are differently affected by the choice of index methodologies and sensitivities to capital market dynamics vary substantially between these two types of indices.

\footnotetext{
${ }^{1}$ As of October 2012, see http://www.eurexchange.com/exchange-en/market-data/statistics/monthlystatistics/

${ }^{2}$ For an overview on the market for dividend derivatives see Manley and Mueller-Glissmann (2008).
} 
Indices are reviewed and maintained on a regular basis and consequently the index composition changes frequently. Thus, long-term effects of index composition changes are of vital relevance for investors in long-dated index derivatives, as investors face the difficulty of a non-deterministic underlying at maturity. For dividend indices this is especially relevant since, at the time of writing, exchange listed dividend derivatives with maturities up to the year 2022 are exchange traded. We analyze in detail the consequences of index composition changes due to regular updating of the set of index member companies.

We propose that the choice of an indexing methodology, including the rebalancing frequency, is an active strategy which has significant implications for long-term index investors. To back this claim, we compare the price and dividend performance of buy-and-hold portfolios invested in the stocks which are members of a specific index, to the performance of a periodically updated index. Our analysis consists of an empirical case study on the Euro Stoxx 50 as well as an extensive simulation study. Our paper has important implications for investors, asset managers, and index providers, by shedding light on the long-term effects of index composition changes, and even more importantly, the consequences of the choice of index weighting methodologies. To the best of our knowledge, we are the first to compare market capitalization weighted indices and fundamentally weighted indices consistently for both, price and dividend indices.

Drawing on our results we are able to reject a common sell-side analysts' claim that dividend indices exhibit a systematic upward bias in the long-run. Institutional investors with long investment horizons such as endowment funds and sovereign wealth funds, frequently track markets passively with reference to a benchmark in those asset classes where performance dispersion between good and bad asset managers is small (public equity developed markets is one of those). Hence, the choice of indexing methods is crucial. We show that fundamentally weighted benchmarks using dividend levels as the relevant selection criterion for weights tend to outperform market-cap weighted indices, especially for large-cap strategies. Rebalancing affects dividend indices more adversely than price indices. Moreover, we highlight the relevance of capital market dynamics, more precisely mean reversion and momentum, for long-term index performance.

The remainder of this paper is organized as follows. In section 2 we present the academic literature related to our paper. We then analyze price and dividend implications of Euro Stoxx 50 composition changes as well as implications of applying different weighting mechanisms, using an empirical case study in section 3. Subsequently, in section 4, we elaborate on our motivation to implement an extensive simulation study to generalize our results, and 
also present the methodology applied to the simulation. Section 5 illustrates our results in detail. Finally, section 6 concludes.

\section{Related Literature}

Since index compositions are reviewed and adjusted periodically, studies on the long-term effects of index composition changes are of vital relevance for investors, as it is crucial to them whether these have systematic effects. Most papers in this area of research look into shortrun effects of stocks included to an equity index or excluded from it. As many researchers found abnormal positive returns of newly included stocks and negative abnormal returns of exluded stocks, several theories have been proposed and empirically tested for. Shleifer (1986) claims that index inclusion is an information free event since index rebalancing is based on criteria that are publicly available. The author finds that abnormal returns (that do not fully reverse) are positively related to buying by index funds and thus concludes that demand curves for stocks slope downward. Moreover, he does not find any evidence for the information hypothesis (which indicates that index inclusion does not provide new information on the quality of the stock), nor does he find evidence for the liquidity hypothesis. The liquidity hypothesis claims that stocks included to an index are more thoroughly scrutinized by investors leading to more liquidity, lower bid-ask spreads and hence a lower required rate of return on that stock. ${ }^{3}$ Similarly, Beneish and Whaley (1996) report permanent abnormal returns of a higher magnitude than earlier studies, which the authors attribute to the increasing wealth indexed to the S\&P 500. The same authors confirm their results in Beneish and Whaley (2002) and report even higher abnormal returns. Some studies find that the abnormal returns reverse fully after some days, supporting (in abscence of any information content of the index adjustment) a price pressure hypothesis. Among those are Harris and Gurel (1986) and Lynch and Mendenhall (1997) who indicate that empirical findings of abnormal return patterns violate the semi-strong form of market efficiency. Other researchers find support for the information hypothesis, thus suggesting that index inclusions or deletions provide information on the quality of a stock. Examples are Jain (1987), Dhillon and Johnson (1991) and Cai (2007). In addition to abnormal stock returns after index composition changes, Denis, McConnell, Ovtchinnikov, and Yu (2003) find that firm fundamentals of newly included companies improve and outperform a peer group (Kappou, Brooks, and Ward (2008) report similar findings $)^{4}$.

\footnotetext{
${ }^{3}$ Studies in support of the liquidity hypothesis are for instance Edmister, Graham, and Pirie (1996) and Erwin and Miller (1998).

${ }^{4}$ For an overview on candidate hypotheses for abnormal returns after index replacements see Kappou, Brooks, and Ward (2008).
} 
Contrary to those papers looking into short-run effects of index inclusions and exclusions, Siegel and Schwartz (2006) calculate the return on a portfolio consisting of the original S\&P 500 companies from 1957 (taking into account spin-offs, bankruptcies, mergers, delistings and so forth) and compare it to the return of the actual index. The authors report that the original companies outperformed the actual index over a period of 46 years and exhibited less risk. This research approach differs from the studies before in two major ways. First it investigates index composition effects over the (very) long-run and second it looks into performance statistics on the index level rather than on the level of individual stocks being added to or deleted from an index. Hence, the index level approach provides more insight into the consequences of index updating for passive investors with long investment horizons. Another paper examining composition effects on the index level is Cai and Houge (2008). For a 25 year period the authors show that a buy-and-hold strategy outperforms the periodically updated Russel 2000 small-cap index, both over the one and five year horizon. Studying index construction methodologies in general, Ranaldo and Haeberle (2008) argue that many equity indices currently available are not really passive proxies for the market. Rather they can be considered to be active management strategies that involve some form of momentum and stop-loss strategies. The more exclusive an index is constructed the more it tends to outperform comparable (less exclusive) indices. Put differently, periodically updated indices outperform passive buy-and-hold strategies (that are only updated for technical reasons like stock splits or right issues etc.). Those results are somewhat in contrast to the very long-run effects analyzed by Siegel and Schwartz (2006).

In addition to price indices, dividend indices become more and more important as underlyings for listed dividend derivatives. As a consequence, an expanding set of empirical data is available for researchers. Recent studies such as van Binsbergen, Hueskes, Koijen, and Vrugt (2012) utilize empirical data on dividend derivatives to investigate the dynamics of the term structure of equity risk premia. More importantly for this paper, though, is the fact that dividend derivatives usually have maturities that reach far into the future. Consequently, one needs to take into account factors influencing dividend payouts, since declining payouts pose a risk to investors in dividend derivatives. Declining payouts have empirically been documented by Fama and French (2001). The authors show that historically dividend payouts have been positively related to firm profitability and firm size, whereas payouts and investment oppurtunities are negatively related. They conclude that declining dividend payouts are both due to changing firm characteristics as well as lower propensity to pay. DeAngelo, DeAngelo, and Skinner (2004) claim that total cash dividends paid by US industrial firms have actually increased despite a smaller fraction of companies paying dividends and lower propensity to pay. This can be reconciled by a high concentration of earnings and dividends among the most 
profitable companies. Denis and Osobov (2008) provide international evidence on dividends and variables influencing dividends that are similar to the results of DeAngelo, DeAngelo, and Skinner (2004) for the US. Even though other theories explaining dividend policy have been supported by researchers (such as the catering theory of dividends, the signaling theory and clientele effects to name just a view) the life cycle theory of dividends seems most consistent with empirical findings. ${ }^{5}$ Inspired by early research of Schumpeter (1934), many academics have studied the life cycle of companies. With respect to dividends, the line of argumentation is as follows: young firms have plenty of profitable investment opportunities which they cannot fully fund internally and thus retain earnings. As companies mature and investment opportunities decline, cash is internally generated at a higher rate than required for profitable investments and is consequently paid out to shareholders. ${ }^{6}$ Common variables that empirically explain part of the variation in dividend payouts (since they proxy for a company's stage in the life cycle) are firm size, firm age and the ratio of retained earnings to total equity. Whereas evidence from the European Union is similar to the international evidence in general, the ratio of retained earnings to total equity does not explain much variation in dividend payouts in this region. However, as payouts and firm age are positively related, the life cycle theory of dividends seems to be supported in the European Union as well (see Eije and Megginson (2008)).

Most equity indices are market capitalization weighted, an approach that is consistent with the CAPM, but has recently received popular critique by Arnott, Hsu, and Moore (2005). The authors argue that already earlier studies reject the mean-variance efficiency of capitalization weighted equity indices. They suggest to reference to fundamental values such as the price-to-book ratio, gross dividends etc. instead. Empirical evidence shows that such fundamental indices outperform traditional market cap weighted indices. One could interpret this as fundamental indices following active investment strategies outperforming market cap weighted indices. Chow, Hsu, Kalesnik, and Little (2011) compare several heuristic-based index construction methodologies as well as several optimization-based weighting methodolgies. The authors find that many index methodologies outperform market capitalization weighting, one of them being fundamental indexing. The study proposes that performance differentials are related to size and value factors. In a similar study, Plyakha (2012) finds performance differences between various index methodologies which are less pronounced.

Since this paper investigates the consequences of different index composition methodologies for price and dividend indices, it is crucial to look into the dynamics exhibited by

\footnotetext{
${ }^{5}$ For a thorough overview of research on dividend policy see Baker (2009).

${ }^{6}$ For a life cycle theory of the firm and dividends see Mueller (1972).
} 
index member stocks. Depending on the parameters for the stochastic processes of stocks, the optimal choice of the index methodology can vary. Balvers, Wu, and Gilliland (2000) empirically find mean reversion in stock markets of different countries. The authors show that over long horizons (half-life of three and a half years) stock indices tend to mean revert to a fundamental value. Furthermore, there is academic evidence that mean reversion can be consistent with equilibrium models (see for instance Balvers, Cosimano, and McDonald (1990)). Moreover, Choi and Kim (2013) provide evidence for momentum in stock returns and propose an equilibrium model that is able to produce momentum effects similiar in magnitude to those observed empirically. Balvers and $\mathrm{Wu}$ (2006) estimate parameters for an integrated mean reversion and momentum model for national stock markets.

\section{A Case Study on the Euro Stoxx 50}

The Euro Stoxx 50 Index is a free-float market capitalization weighted equity index that comprises blue-chip stocks from the Eurozone countries. A special feature of the Euro Stoxx 50 is that the index provider applies the same index weighting mechanism also to gross ordinary dividends announced and paid by the Euro Stoxx 50 member companies. ${ }^{7}$ The result is the Euro Stoxx 50 DVP (Dividend Point) Index.

Both, the Euro Stoxx 50 price index and the Euro Stoxx 50 dividend index are reviewed once a year (stocks that do not longer qualify for index membership according to free-float market capitalization are replaced) and additionally maintained via a fast exit and fast entry rule. Since the same methodology underlies both indices (index composition changes resulting from the annual review or ongoing maintenance are applied to both indices) analysis of Euro Stoxx 50 data offers the opportunity to assess the long-term effects of index composition changes on the price and dividend index level using one consistent methodology.

Our analysis is of vital relevance for investment practitioners, since it has become a common sell side analysts' argument that long-term investment products on equity indices and especially on dividend indices are attractive because of a systematic upward bias due to index composition changes. More precisely, sell side analysts claim that companies with poor future prospects tend to be replaced by companies which are more likely to pay (higher) dividends and prosper more. If this were true, long term investors of index tracking products would benefit from index composition changes (as opposed to investors who replicate an index by purchasing all member stocks and holding them). We analyze whether this claim holds em-

\footnotetext{
${ }^{7}$ For a detailed description of the Euro Stoxx 50 methodology see Stoxx (2012b), and see Stoxx (2012a) for the Euro Stoxx 50 DVP Index.
} 
pirically true.

Similar to most of the studies on single stock effects of index composition changes, we start with the assumption that changes of the index composition do not have any information content in the sense that prospects for future index returns change. As the Euro Stoxx 50 indices are weighted by free-float market capitalization and this is also the relevant criterion for index inclusion or exclusion, this is a reasonable assumption. This is even more true for the index prospects than for the prospects of single stocks involved in an index replacement. As a result, we would a priori not expect index composition changes to have a systematic impact on the subsequent performance of the price index. With regards to the dividend index, one needs to consider the determinants of dividend payouts (put differently the payout ratio) as it could be possible that companies added to the index have a systematically higher propensity to pay dividends without violating the no information content assumption. Consequently, we will analyze common proxy variables that empirically influence payout ratios, at the time of index composition changes.

\subsection{Data and Methodology}

This section describes the data and defines those index composition changes which we consider as relevant events in our study. Subsequently, we elaborate on the methodology applied to implement purely passive indices that are a representation of the price performance and dividend payouts an investor replicating the Euro Stoxx 50 via single stocks would receive.

\subsubsection{Data}

We gather data of the Euro Stoxx 50 price index, the Euro Stoxx 50 dividend index as well as data of all constituents from January 2002 to December 2011 with daily frequency. For the price index, we obtain the time series of index prices and the index divisor, for the dividend index we download dividend levels from January 2005 to December 2011 (the Euro Stoxx 50 dividend index was only launched in 2008 and backfilled to 2005, see Stoxx (2008)) ${ }^{8}$. For each company that was an index member at least at one point in the sample period, we download daily stock prices, dividends announced and paid, and adjustment factors (factors related to corporate actions such as stock splits and other actions that lead data providers to restate historical data). In addition, we obtain the weights of each company in the index on a daily basis. The data source for all time series is Bloomberg.

\footnotetext{
${ }^{8}$ We use the dowloaded dividend index to cross check our calculation of the dividend index.
} 
For the construction of the passive buy-and-hold portfolios described below in section 3.1.3, we require uninterrupted time series of prices and dividends for all companies in our sample. To achieve this, mergers and aquisitions have to be taken into account. In such cases we combine the time series of the acquiring company and the target company using a conversion factor reflecting the terms offered to investors of the target company at the time of the merger or acquisition. Put differently, we construct our time series to match the performance of a buy-and-hold investor of the original company. We download the conversion factors from Bloomberg and cross check it with annual reports of the companies involved.

In order to reconstruct the Euro Stoxx 50 price index and to calculate the dividend index for the whole sample period we need to back out the number of shares in the index of each company. The number of shares is assigned uniquely to each company from the index provider. Using available data the number of shares $n$ for company $i$ at time $t$ can be backed out as $n_{i, t}=\frac{w_{i, t} \cdot P I_{t} \cdot \text { divisor }_{t}}{s_{i, t}^{\text {undj }}}$, where $w_{i, t}$ is the weight of stock $i$ in the index, $P I_{t}$ is the Euro Stoxx 50 price index at time $t$ and $s_{i, t}^{u n a d j}$ is the unadjusted stock price of company $i$ at time $t^{9}$. We calculate the dividend index for the whole sample period as follows. The daily increment $D P_{t}$ to the dividend index is

$$
D P_{t}=\sum_{i=1}^{50} \frac{n_{i, t} \cdot d_{i, t}^{\text {unadj }}}{\text { divisor }_{t}}
$$

where $d_{i, t}^{\text {unadj }}$ are the unadjusted dividends of company $i$ at time $t$. Summing over time yields the dividend index $D I_{t}$

$$
D I_{t}=\sum_{\tau=\tau_{m}}^{t} D P_{\tau}
$$

Note that the dividend index is reset to zero each third friday in december, $\tau_{m}$. For an illustration of the dividend index see Figure 10 in the appendix.

To form an expectation on the dividend impact of index composition changes we gather data on two well documented variables that proxy for a company's stage in the (dividend-) life cycle: the book value of equity and the ratio of retained earnings to total equity (see for instance Fama and French (2001), Denis and Osobov (2008) and Eije and Megginson (2008)). This data is only collected for companies added to or deleted from the Euro Stoxx

\footnotetext{
${ }^{9}$ To be precise the numer of shares $n_{i, t}$ used here corresponds to the number of shares multiplied by the free-float factor and the weighting-cap factor in the Stoxx definition.

$s_{i, t}^{u \text { udj }}$ indicates that we use stock prices as they really were historically, not as data providers quote it. One can get unadjusted stockprices by undoing the adjustments data providers implement to make charts and time series smooth using the adjustment factors. The same is true for unadjusted dividends.
} 
50. We evaluate the data on the nearest possible date to the addition/deletion date. The data sources are Bloomberg and annual reports.

Finally, we use a list of all companies added to or deleted from the Euro Stoxx 50, from the webpage of Stoxx to define the relevant events. ${ }^{10}$ The following subsection will elaborate on the definition of those events.

\subsubsection{Event Definition}

The weights $w_{i, t}$ of a free-float market capitalization weighted index do change over time due to performance dispersion of the member stocks. However, this is not considered as an index composition change since the number of shares in the index of each member company is not affected. Another case is a change in the number of shares in the index of a specific company resulting in a reweighting of all member companies (without any company being added to or deleted from the index). Possible reasons for such a reweighting can be changes in the free-float of one or more companies, weighting cap factors becoming effective or discretionary changes by the index provider. Since the set of member companies stays constant in this case, we do not define such pure reweightings as events either.

Our definition of an event is only the strongest form of a reweighting, where at least one company in the index is replaced by another company. In addition to one or more stocks being replaced, such an event causes the whole set of member companies to be reweighted (except for the unlikely case that the newly added company is assigned exactly the same weight as the deleted company previously had). Whenever corporate actions of index members occur or replacements are implemented, the index divisor is adjusted to keep the value of the index independent of such a case. The index is designed to change only when stock prices of member companies fluctuate due to market action, but not when they change due to technical adjustments. Note that an event can be caused by a merger or acquisition of two member companies. This does not only lead to a reweighting of the set of member companies, but also leads to the addition of a new company in order to keep the number of member companies in the index equal to 50.

We introduce one additional constraint with respect to the event definition: only one event is considered per calender day. Thus, in those cases where more than one company is replaced on the same day we consider the combined effect of all replacements and the resulting

\footnotetext{
${ }^{10} \mathrm{We}$ compose the list from the component change announcements made on http://www.stoxx.com/indices/index_information.html?symbol=SX5E. Furthermore, we composed a second list using the daily index weights for all companies in our sample. Both lists do match.
} 
reweightings as a single event. According to our data we have 22 index replacements in the sample period. There are 3 instances where more than one stock is replaced on the same day reducing the relevant index composition changes to 19. We drop 3 further replacements as the legal entities involved belong to the same company in economic terms. Finally, we drop the very recent (2011) replacements as we do not have enough data subsequent to the replacement to assess the effect of these composition changes. So we are eventually left with 13 events. $^{11}$

\subsubsection{Passive Portfolios}

To assess the effects of index composition changes on the price and dividend index, it is necessary to compare the actual indices to a set of benchmark portfolios that reflect the price and dividend performance, which a buy-and-hold investor of a replicating portfolio would get. In practical terms, we need to compare the performance of a hypothetical investor $A$ in an index tracking product like index futures or ETFs, where the underlying is updated regularly in accordance with the changes announced by the index provider, to the performance of a hypothetical buy-and-hold investor $B$ who invests in the actual member stocks of the index (and weights the 50 stocks according to free-float market capitalization) ${ }^{12}$. Both investors are affected in the same way by the fluctuation of weights due to dispersion in the performance of member companies. Corporate actions such as stock splits are neutral to both investors. However, investor $A$ is forced to participate in index composition changes (events) through the index tracking product, whereas investor $B$ as a buy-and-hold investor in the underlying stocks is unaffected by the event. Thus, in order to investigate whether index composition changes have systematic effects on investors in products tracking the Euro Stoxx 50 price or dividend index (investors of type $A$ ), we need to compare the price and dividend performance of investor $A$ to a set of investors $B$.

\footnotetext{
${ }^{11}$ For the pairwise comparisons in section 3.2.2 we have more observations because we can analyze multiple replacements on one day seperately in this case. For the analysis of the company fundamentals at the time of replacement the number of observation differs again slightly, due to data availability for those legal entities that cease to exist after a merger or acquisition. With respect to the risk-return characteristics of index composition changes the number of observations differs between the market beta regressions and the FamaFrench regressions since we can use weekly data for the first set of regressions but only monthly data for the latter set of regression due to availability of the size and value factors. The number of observations is higher, though, for both sets of regressions than for the performance comparison on the index level as we do not exclude those instances where two seperate legal entities of the same economic entity are involved. This seems reasonable as the merged entity could possibly have an incremental impact on the size or value factor laodings.

${ }^{12}$ Index tracking products for the dividend index could be dividend futures as mentioned in section 3 . However, there also exist ETFs that replicate the performance of a long position in dividend futures. See for instance http://www.lyxoretf.co.uk/homeuk0/products/country/UK/product/286570/ for the Lyxor ETF Euro Stoxx 50 Dividends EUR.
} 
The actual price index is calculated as ${ }^{13}$

$$
P I_{t}=\sum_{i=1}^{50} \frac{n_{i, t} \cdot s_{i, t}^{u n a d j}}{\text { divisor }_{t}}
$$

On every event date we launch a passive buy-and-hold portfolio investing in the stocks that were index members immediately before the replacement took place. Thus, every passive portfolio represents the price performance of an investor of type $B$, who invested just before the event. The passive buy-and-hold portfolios $P I_{t}^{*}$ are calculated as:

$$
P I_{t}^{*}=\sum_{i=1}^{50} \frac{n_{i, t}^{*} \cdot s_{i, t}^{\text {unadj }}}{\text { divisor }_{t}^{*}}
$$

where $n_{i, t}^{*}$ is independent from discretionary changes implemented by the index provider (i.e. independent from the consequences of index replacements or discretionary reweightings unrelated to performance dispersion of index member stocks). However, $n_{i, t}^{*}$ is not constant since it needs to account for corporate actions such as stock splits. The same is true for divisor $_{t}^{*}$. The reason that divisor* $t_{t}^{*}$ is not constant is that for some corporate actions (for instance rights issues) the increase (decrease) in share price is not exactly compensated by a decrease (increase) in the number of shares. Hence, divisor ${ }_{t}^{*}$ is adjusted to keep the portfolio value unaffected. We implement a passive portfolio everytime an event occurs. Since we define 13 events we implement 13 passive buy-and-hold portfolios. Equation 1 and 2 in section 3.1.1 already presented how the actual dividend index can be calculated. Equivalent to the logic applied for the price index we launch a passive dividend index $D I_{t}^{*}$ on every event date:

$$
\begin{gathered}
D P_{t}^{*}=\sum_{i=1}^{50} \frac{n_{i, t}^{*} \cdot d_{i, t}^{\text {unadj }}}{\text { divisor }}{ }_{t}^{*} \\
D I_{t}^{*}=\sum_{\tau=\tau_{m}}^{t} D P_{\tau}^{*}
\end{gathered}
$$

where $D P_{t}^{*}$ are the daily increments of the passive dividend indices. It is important to note that we apply the same methodology for the passive price portfolio and the passive dividend index. As a consequence, we use the same $n_{i, t}^{*}$ and divisor $t_{t}^{*}$ for both. To make our results independent from calender time we compare the actual indices to the passive indices one, two, and three years following an event. Put differently, by comparing the price and dividend performance of an investor of type $A$ to a hypothetical set of 13 investors of type $B$ in relative time, we shed light on the price and dividend implications of index composition changes.

\footnotetext{
${ }^{13}$ The resulting price index time series matches the Euro Stoxx 50 index time series from Bloomberg.
} 


\subsection{Results}

After having elaborated on the data and the methodology applied for the case study, this section presents the results as follows: By looking into common proxy variables predicting subsequent dividend payouts we form our expectation on the dividend effect of index composition changes. Subsequently, we show the main results on the consequences of index repacements. We then dig deeper into the anatomy of the effects by comparing pairwise the price and dividend performance of stocks added to and deleted from the Euro Stoxx 50. Finally, we report findings on the differences in risk-return characteristics of the actual indices and the passive portfolios.

\subsubsection{Company Fundamentals and Dividends}

According to the life cycle theory of dividends more mature companies are more likely to pay (higher) dividends. Common proxy variables for the life cycle theory of dividends in the literature are the book value of equity and the ratio of retained earnings to total equity (see for instance Fama and French (2001), Denis and Osobov (2008) and Eije and Megginson (2008)). Thus, it is interesting to look into these accounting variables of companies added to and deleted from the Euro Stoxx 50. Table 1 lists the relevant event dates. For each event date it provides the company added to the Euro Stoxx 50, the company deleted from the index and the following variables: $\Delta$ Total Equity is the difference between the book value of the added company and the deleted company (added company minus deleted company) in billion euros, $\Delta$ Ratio Ret. Earnings / Tot. Equity is the difference between the ratio of retained earnings to total equity of the added and the deleted company in percentage points and $\triangle$ Market Cap is the difference between the the market capitalization of the added and the deleted company in billion euros. 


\begin{tabular}{lllrrr}
\hline Event Date & Added Company & Deleted Company & $\begin{array}{r}\Delta \text { Total } \\
\text { Equity }\end{array}$ & $\begin{array}{r}\Delta \text { Ratio Ret. } \\
\text { Earnings } / \text { Tot. Equity }\end{array}$ & $\begin{array}{r}\Delta \text { Market } \\
\text { Cap }\end{array}$ \\
\hline 23.09 .02 & Lafarge & PPR & 2.60 & $-4.28 \%$ & -1.55 \\
22.09 .03 & Iberdrola & Bayrische HVB & -4.65 & $43.20 \%$ & 5.88 \\
28.07 .04 & SAP & Aventis & -6.46 & $200.26 \%$ & -6.67 \\
20.09 .04 & Credit Agricole & Volkswagen & 3.68 & $-52.92 \%$ & 15.85 \\
30.06 .05 & Allied Irish Banks & Telecom Italia M & -0.56 & $-6.13 \%$ & -29.11 \\
20.07 .05 & Renault & Royal Dutch & -23.78 & $11.09 \%$ & -75.24 \\
24.09 .07 & Vinci & Lafarge & -4.15 & $-15.60 \%$ & 3.08 \\
24.09 .07 & Schneider Electrics & Allied Irish Banks & -0.81 & $-41.27 \%$ & 7.41 \\
24.09 .07 & Arcelormittal & Ahold & 57.73 & $296.91 \%$ & 64.73 \\
10.10 .07 & Volkswagen & Endesa & 19.28 & $71.41 \%$ & -0.69 \\
15.10 .07 & Deutsche Börse & ABN Amro & -23.61 & $-17.01 \%$ & -46.52 \\
22.09 .08 & Alstom & Alcatel Lucent & -9.46 & $73.51 \%$ & 10.42 \\
21.09 .09 & CRH PLC & Renault & -11.26 & $75.36 \%$ & 3.83 \\
21.09 .09 & Anheuser Busch & Fortis (Ageas) & -9.76 & $14.85 \%$ & 32.37 \\
08.02 .10 & Unibail Rodamco & Volkswagen & -24.95 & $-65.14 \%$ & -27.56 \\
20.09 .10 & BMW & Aegon & 1.34 & $44.84 \%$ & 17.99 \\
19.09 .11 & Inditex & Credit Agricole & -47.19 & $70.85 \%$ & 11.56 \\
19.09 .11 & Volkswagen Pref & Alstom & 51.53 & $11.32 \%$ & 49.15 \\
\hline Mean & & & -1.69 & $39.51 \%$ & 1.94 \\
Median & & & -4.40 & $13.09 \%$ & 4.85 \\
\hline
\end{tabular}

Table 1: Index Replacements. Event Dates are dates on which relevant index replacements took place. Added Company and Deleted Company provide the companies involved in the replacement. $\Delta$ Total Equity is the book value of equity of the added company minus the corresponding number for the deleted company in billion euros. $\Delta$ Ratio Ret. Earnings / Tot. Equity is the difference between the ratio of retained earnings to total equity of the added and the deleted company in percentage points. $\triangle$ Market Cap is the difference between the total market capitalization of the added company and the deleted company in billion euros. All three variables are measured on the closest available date to the event.

Firstly, both mean and median of $\Delta$ Market Cap show that companies added to the index are larger in terms of market capitalization than the companies deleted. This is not surprising since the Euro Stoxx 50 is weighted by market capitalization ${ }^{14}$. However, due to mergers and acquisitions (and other events such as a change of listing to a non-Eurozone country) not every event has to be caused by the market capitalization of the added company exceeding the market capitalization of the deleted company. More importantly, according to mean and median of $\Delta$ Total Equity companies added to the Euro Stoxx 50 are smaller than those deleted in terms of book values. Thus, in a life cycle theory of dividends context one could interpret the negative sign of $\Delta$ Total Equity as firms added to the index being less likely to pay (higher) dividends than those firms deleted from the index, resulting in the expectation of the dividend implications of index composition changes being negative (unless other effects such as the reweighting of the set of index member companies after index replacements more than compensate for the decreased dividend expectation from a fundamental point of view). However, taking into account the positive sign of $\Delta$ Ratio Ret. Earnings / Tot. Equity leads to exactly the opposite conclusion for the dividend effect. Since Eije and Megginson (2008) find that company size is a better predictor for dividend payouts in the European Union

\footnotetext{
${ }^{14}$ To be precise, $\triangle$ Market $C a p$ is the total market capitalization outstanding whereas the Euro Stoxx 50 is weighted by free-float market capitalization. However, none of the events listed in Table 1 is caused by a significant change in the free float factor.
} 
than the ratio of retained earnings to total equity, one could assign $\Delta$ Total Equity a higher weight when it comes to interpreting the results. Nevertheless, as this cannot be quantified and all of the potential Euro Stoxx 50 member companies can be considered to be very large companies it is questionable if there is any significant influence of the proxy variables on subsequent differences in dividend payouts. Consequently, we would not expect index composition changes to have any significant effects on the Euro Stoxx 50 dividend index.

\subsubsection{Effects of Euro Stoxx 50 Composition Changes}

Table 2 provides summary statistics for the comparison of the actual price and dividend index to the passive portfolios. We identify 13 events for which we calculate mean, median, minimum and maximum for the differences in year one. We lose observations when we assess the effects two and three years following an event. ${ }^{15}$ As Panel A in Table 2 shows, both means and medians of the dividend effect are negative for all three years. The biggest effect can be observed in year one after the events, then the effect declines or partially reverses depending on whether means or medians are taken. Note that effects are cumulative over time. Hence, an effect of -72 basis points in year one and -56 basis points in year two means a positive change from year one to year two. However, the effect is economically small (-56 basis points over three years). The dividend effect is not significantly different from zero in all three years. This finding is consistent with our expectation, as our results in section 3.2.1 do not provide clear evidence for a change of the relevant fundamental variables through index replacements. Moreover, it contradicts the common sell-side analysts' opinion of a positive and systematic effect on the dividend index (the sign in this study is negative and since the effect is statistically insignificant it cannot be considered to be systematic).

Panel B in Table 2 indicates that the effect on the price index is positive. According to the means, the effect is slightly larger in magnitude than for dividends (71 basis points over three years). Again the effect is most prominent in year one and reverses partially thereafter. Even though mean and median are consistent over the three year evaluation period, they differ in year one and two. Similar to the dividend effect, the price effect is not statistically different from zero in all three years. This is consistent with the notion that index composition changes are information free events. Looking into dividends and prices together, we can reject the null hypothesis that both effects are equal in year one and barely in year two, but not in year three. ${ }^{16}$ On the basis of our empirical sample, this leads to the conclusion that price and dividend effects diverge in the first year after an event, where the price effect tends to

\footnotetext{
${ }^{15}$ From year one to year two the number of observations decreases by two, because there are events in the sample that aggregate more than one index replacement on the same day.

${ }^{16}$ t-statistics of a two sided test of 4.0194 in year one and 2.7416 in year two
} 
be positive in sign whereas the dividend effect tends to be negative in sign. However, the long-term consequences (after three years) are inconclusive.

Panel A. Dividends.

\begin{tabular}{lccc}
\hline & year +1 & year +2 & year +3 \\
\hline Mean & -0.0072 & -0.0056 & -0.0056 \\
Median & -0.0075 & -0.0085 & -0.0017 \\
Min & -0.0342 & -0.0267 & -0.0366 \\
Max & 0.0210 & 0.0483 & 0.0121 \\
Nr of obs. & 13 & 11 & 10 \\
\hline
\end{tabular}

Panel B. Price Index.

\begin{tabular}{lccc}
\hline & year +1 & year +2 & year +3 \\
\hline Mean & 0.0102 & 0.0100 & 0.0071 \\
Median & 0.0001 & 0.0029 & 0.0074 \\
Min & -0.0068 & -0.0094 & -0.0307 \\
Max & 0.0512 & 0.0432 & 0.0414 \\
Nr of obs. & 13 & 11 & 10 \\
\hline
\end{tabular}

Table 2: Summary Statistics of Index Differences. Panel A reports means, medians, minimums and maximums over all comparisons of the actual Euro Stoxx 50 dividend index to the passive dividend portfolios. Panel B reports the corresponding results for the comparisons of the actual Euro Stoxx 50 price index to the passive price portfolios. The reported effects are cumulative and not on a per annum basis. $N r$ of obs. is an abbriviation for the number of observations (the number of comparisons).

Remember that we aggregate all index replacements that occur on the same date into one event. Moreover, we already discussed that index replacements cause a reweighting of the whole set of index member companies. As a consequence, comparing pairwise the subsequent price and dividend performance of the companies added to and deleted from the index need not necessarily yield the same results as the comparison on the index level. Thus, we perform pairwise comparisons to shed more light on the anatomy of the effects of index composition changes. Panel A of Table 3 reveals that companies added to the index pay 37 basis points more dividends over the three years following an event. The positive sign is in contrast to the dividend effect on the index level. This can be interpreted as the effect of the newly added companies paying marginally higher dividends being more than offset by an opposite effect caused by the reweighting of the set of member companies. The dividend effect is not statistically different from zero in all three years, though. Panel B of Table 3 indicates that the combined price effect over three years is negative for the pairwise comparison. As can be seen from the minimum, the results are influenced by an outlier. Despite the large magnitude of the price effect it is not significantly different from zero in statistical terms. 
Additionally, the dividend and the price effect are not statistically different from each other using the pairwise comparisons.

What we can learn from the results presented in this section is that it does not suffice to look into the price and dividend performance of single stocks involved in index replacements to assess the effect of composition changes on the index level. Reweightings caused by index replacement can potentially more than offset the pairwise performance differences between added and deleted stocks. As both price and dividend effects are statistically indistinguishable from zero on the index and the single stock level, our results are consistent with the notion that index composition changes are information free events. Moreover, we can reject a common sales argument that dividend indices exhibit a systematic positive bias. The results on the index level indicate, however, that an index composition change might have diverging consequences for the price and dividend index respectively. In economic terms it seems to be slightly more favourable for the price index.

Panel A. Dividends.

\begin{tabular}{lccc}
\hline & year +1 & year +2 & year +3 \\
\hline Mean & 0.0020 & -0.0023 & 0.0027 \\
Median & 0.0000 & 0.0001 & 0.0036 \\
Min & -0.0244 & -0.1198 & -0.0654 \\
Max & 0.0423 & 0.0497 & 0.0437 \\
Nr of obs. & 21 & 19 & 15 \\
\hline & & & \\
& Panel B. Prices. & \\
\hline & year +1 & year +2 & year +3 \\
\hline Mean & 0.0374 & 0.0033 & -0.2620 \\
Median & 0.0000 & 0.0000 & -0.0579 \\
Min & -0.7580 & -1.1949 & -3.7427 \\
Max & 0.7350 & 1.0490 & 1.2091 \\
Nr of obs. & 21 & 19 & 15 \\
\hline
\end{tabular}

Table 3: Summary Statistics of Replacements. Panel A reports means, medians, minimums and maximums over all comparisons of prices of the companies added to the index versus the companies deleted from the index. Panel B reports the corresponding results for the comparisons of the dividends paid by companies added to the index versus those paid by companies deleted from the index subsequent to an index replacement. The reported effects are cumulative and not on a per annum basis. $\mathrm{Nr}$ of obs. is an abbriviation for the number of observations (the number of comparisons). 


\subsubsection{Effects on the Risk-Return Characteristics of the Price Index}

It is interesting to investigate whether index composition changes have a systematic effect on the risk-adjusted price return of the index. Hence, we regress the returns of the passive price portfolios on the return of the actual Euro Stoxx 50 price index, again using three years of data subsequent to the events. The regression reads as:

$$
R_{t}^{*}=\alpha+\beta \cdot R_{t}
$$

where $R_{i}^{*}$ is the return of a passive price portfolio and $R_{i}$ is the return of the actual Euro Stoxx 50 price index. We perform this regression for each passive price portfolio over up to three years subsequent to the respective event using the corresponding three year window of actual Euro Stoxx 50 price returns as the regressor. The data frequency is weekly. Table 4 provides the date on which a specific passive portfolio was launched, betas and alphas as well as t-statistics.

\begin{tabular}{rrrrrrc}
\hline \multicolumn{1}{c}{ Start date } & Beta & $t(\beta \neq 0)$ & $t(\beta \neq 1)$ & Alpha & $t$-stat & $R^{2}$ \\
\hline 22. Sep. 2002 & 0.98936 & 338.98 & -3.65 & 0.00016 & 2.18 & 0.99866 \\
21. Sep. 2003 & 0.98677 & 151.79 & -2.03 & 0.00000 & 0.03 & 0.99336 \\
27. Jul. 2004 & 0.98124 & 140.30 & -2.68 & 0.00013 & 1.02 & 0.99229 \\
18. Sep. 2004 & 0.98843 & 140.74 & -1.65 & 0.00021 & 1.60 & 0.99228 \\
30. Jun. 2005 & 0.96847 & 97.28 & -3.17 & -0.00008 & -0.36 & 0.98388 \\
19. Jul. 2005 & 0.96494 & 97.11 & -3.53 & -0.00015 & -0.68 & 0.98383 \\
22. Sep. 2007 & 0.98924 & 121.39 & -1.32 & -0.00030 & -0.87 & 0.98959 \\
9. Okt. 2007 & 1.00259 & 133.03 & 0.34 & -0.00025 & -0.76 & 0.99132 \\
13. Okt. 2007 & 0.99596 & 231.90 & -0.94 & -0.00028 & -1.50 & 0.99713 \\
19. Sep. 2008 & 0.99709 & 575.60 & -1.68 & -0.00010 & -1.25 & 0.99954 \\
19. Sep. 2009 & 1.00735 & 443.05 & 3.23 & -0.00009 & -1.11 & 0.99940 \\
6. Feb. 2010 & 1.00426 & 520.18 & 2.21 & -0.00004 & -0.52 & 0.99964 \\
19. Sep. 2010 & 1.00137 & 360.45 & 0.49 & -0.00005 & -0.49 & 0.99950 \\
16. Sep. 2011 & 1.01183 & 241.67 & 2.83 & -0.00006 & -0.28 & 0.99976 \\
\hline Mean & 0.99206 & & & -0.00006 & & \\
\hline
\end{tabular}

Table 4: Single Factor Model Regressions. The Start dates are the dates on which the three year evaluation period for the respective regression begins. For each regression of a specific passive portfolio return on the corresponding actual Euro Stoxx 50 price return the table provides coefficients for beta and alpha. Moreover it provides t-statistics for the null hypothesis of beta and alpha being zero, respectively. Furthermore, t-statistics for the null hypothesis beta is equal to one are provided. The data frequency is weekly. 
It can be seen that the beta coefficients are close to, but not exactly equal to one (For most passive portfolios the beta coefficient is different from one in statistical terms $)^{17}$. Alphas are economically small and statistically insignificant. Interestingly, beta coefficients tend to be slightly below one for the passive portfolios launched after events that happened early in the sample, whereas they tend to be slighly above one for the later data points.

Since current academic studies on systematic differences between various index methodologies focus a lot on loadings on the Fama and French factors, especially the size factor (see for instance Chow, Hsu, Kalesnik, and Little (2011)), we implement additionally a three factor Fama and French (1993) type model for the set of regressions:

$$
R_{t}^{*}=\alpha+\beta_{\text {market }} \cdot R_{t}+\beta_{\text {size }} \cdot R_{t}^{S M B}+\beta_{\text {value }} \cdot R_{t}^{H M L}
$$

where $R_{t}^{S M B}$ and $R_{t}^{H M L}$ are the factor returns on European portfolios sorted by size and book-to-market respectively ${ }^{18}$. Table 5 shows the results for the three factor model. Adding size and value factors improves the fit of the regressions, and market betas are closer to one and in most cases statistically indistinguishable from one. Factor loadings on the size factor are insignificant, whereas some of the factor loadings on the value factor are statistically significant.

Overall, the risk-return characteristics of the passive price portfolios are very similar to those of the actual Euro Stoxx 50 price index. This is hardly surprising. As the three factor model brings the market beta coefficients closer to one, it seems that the minor discrepancy of the risk-adjusted returns between the index and the passive portfolios is partially related to size and value factors.

\footnotetext{
${ }^{17}$ Unsurprisingly, for all passive portfolios we can reject the null hypothesis that beta is equal to zero.

${ }^{18}$ The factor returns are taken from Kenneth French's website. Due to data availability we use monthly data here.
} 


\begin{tabular}{rcrrrrrrrr}
\hline Start date & Beta & $t(\beta \neq 1)$ & SMB & $t$-stat & HML & $t$-stat & Alpha & $t$-stat & $R^{2}$ \\
\hline 22. Sep. 02 & 0.99480 & -0.55 & 0.01336 & 0.55 & -0.03454 & -1.00 & 0.00091 & 1.81 & 0.99810 \\
21. Sep. 03 & 0.97774 & -0.98 & -0.01627 & -0.42 & 0.07973 & 1.04 & -0.00016 & -0.23 & 0.98917 \\
27. Jul. 04 & 0.97604 & -0.89 & -0.02323 & -0.49 & 0.01136 & 0.11 & 0.00064 & 0.77 & 0.98242 \\
18. Sep. 04 & 0.99450 & -0.17 & -0.01231 & -0.25 & -0.02936 & -0.23 & 0.00088 & 1.06 & 0.98125 \\
30. Jun. 05 & 1.01513 & 0.67 & 0.01775 & 0.36 & -0.22274 & -2.27 & 0.00006 & 0.07 & 0.98427 \\
19. Jul. 05 & 1.00111 & 0.05 & 0.02742 & 0.57 & -0.22565 & -2.31 & 0.00010 & 0.12 & 0.98747 \\
22. Sep. 07 & 1.01052 & 0.46 & 0.09197 & 1.85 & -0.00619 & -0.11 & -0.00098 & -0.81 & 0.98998 \\
9. Okt. 07 & 1.04559 & 1.87 & 0.12290 & 2.34 & -0.04450 & -0.74 & -0.00048 & -0.38 & 0.98934 \\
13. Okt. 07 & 1.00240 & 0.15 & 0.02698 & 0.80 & -0.02118 & -0.55 & -0.00119 & -1.45 & 0.99530 \\
19. Sep. 08 & 1.00319 & 0.40 & 0.00589 & 0.37 & -0.00577 & -0.30 & -0.00049 & -1.42 & 0.99916 \\
19. Sep. 09 & 0.99850 & -0.20 & 0.00132 & 0.08 & 0.03348 & 2.07 & -0.00009 & -0.31 & 0.99948 \\
6. Feb. 10 & 0.98661 & -2.00 & -0.00693 & -0.43 & 0.03543 & 2.48 & -0.00008 & -0.32 & 0.99968 \\
19. Sep. 10 & 0.98245 & -2.16 & 0.00114 & 0.05 & 0.03979 & 1.95 & 0.00003 & 0.07 & 0.99965 \\
\hline Mean & 0.99912 & & 0.01923 & & -0.03001 & & -0.00007 & & \\
\hline
\end{tabular}

Table 5: Three Factor Model Regressions. The start dates are the dates on which the three year evaluation period for the respective regression begins. Each passive price portfolio's return is regressed on a constant, the corresponding 3 year return window of the actual Euro Stoxx 50 price index, the returns on a portfolio sorted by size and on the returns of a portfolio sorted by book-to-market. Beta is the loading to the actual Euro Stoxx 50 price index return, SMB is the loading to the returns of the size portfolio and HML is the loading to the returns of the book-to-market portfolio. t-statistics are for the null hypothesis coefficient is equal to zero except for the market beta where the null hypothesis is that beta is equal to one. The data frequency is monthly.

\subsection{Comparison of Index Methods}

We now turn to investigate the risk-return characteristics of different index methodologies. Again using data on the Euro Stoxx 50 index as well as on dividends paid by member companies, we aggregate the index universe according to four weighting mechanisms. Since we apply those index construction rules to both, prices and dividends we can disentangle the relative performance impact for a total return investor into a price and a dividend contribution.

Our reference is the Euro Stoxx 50 price index and the respective dividend index. However, we adapt the original index method slighly, since we rebalance the index only once a year in december, $m$. We construct the price index as follows:

$$
P I_{t}^{\prime}=\sum_{i=1}^{50} w_{i, t}^{\prime} \cdot s_{i, t}
$$

where $w_{i, t}^{\prime}$ are index weights and $s_{i, t}$ adjusted stock prices of the constituent companies. The 
corresponding dividend index is calculated from adjusted dividends as:

$$
\left\{\begin{array}{l}
D P_{t}^{\prime}=\sum_{i=1}^{50} w_{i, t}^{\prime} \cdot d_{i, t} \quad \forall \quad t \\
D I_{m}^{\prime}=\sum_{\tau=m-1}^{m} D P_{\tau}^{\prime}
\end{array}\right.
$$

We obtain the annual price contribution to the total return as

$$
P C_{m}=\frac{P I_{m}^{\prime}}{P I_{m-1}^{\prime}}-1
$$

and the dividend contribution as

$$
D C_{m}=\frac{D I_{m}^{\prime}}{P I_{m-1}^{\prime}}-1
$$

Adding price and dividend contributions yields the total return. We vary the index weights in three ways. Firstly, we analyze an index comprising only the 20 largest stocks of the Euro Stoxx 50 universe in terms of market capitalization. To achieve this, we rank the index weights of the reference index and denote the ranked weights by $w_{[j]}$. Subsequently, we obtain the weights for the large-cap 20 index as:

$$
w_{[j]}^{\text {large } 20}=\left\{\begin{array}{ccc}
\frac{w_{[j]}^{\prime}}{\sum_{j=1}^{20} w_{[j]}^{\prime}} & \forall & {[j] \leq 20} \\
0 & \forall & {[j]>20}
\end{array}\right.
$$

Similarly, we get the respective weights for an index comprising the smallest 20 stocks from the Euro Stoxx 50 universe as:

$$
w_{[j]}^{m i d 20}=\left\{\begin{array}{ccc}
\frac{w_{[j]}^{\prime}}{\sum_{j=31}^{50} w_{[j]}^{\prime}} & \forall & {[j]>30} \\
0 & \forall & {[j] \leq 30}
\end{array}\right.
$$

Finally, we construct a fundamental index where we use trailing 12 month dividend levels to weight the index constituents. Thus, fundamental weights can be obtained as

$$
w_{m, i}^{F d i v 50}=\frac{\sum_{\tau=m-1}^{m} d_{i, \tau}}{\sum_{i=1}^{50} \sum_{\tau=m-1}^{m} d_{i, \tau}}
$$

Using these weights, we construct four price-, dividend- and total return indices, respectively. Figures 1, 2 and 3 illustrate how those indices develop over our sample period. 
Price Indices

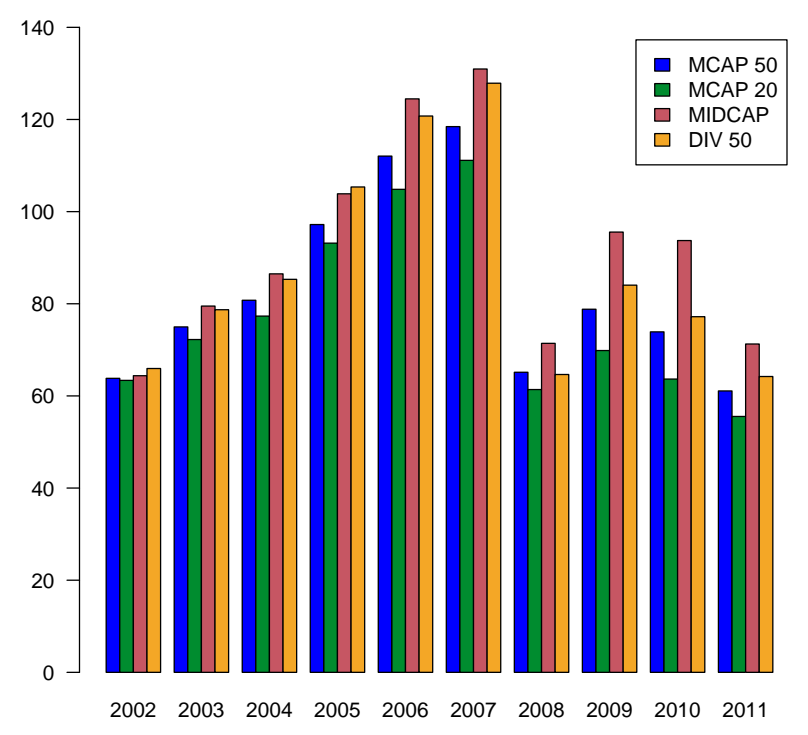

Figure 1: Price Indices This figure illustrates price index levels using four different index construction rules. Blue bars represent the reference index which matches the Euro Stoxx 50, green bars represent a large-cap index comprising the 20 largest stocks, red bars represent an index comprising the 20 smallest stocks of the Euro Stoxx 50 universe and orange bars represent a fundamental index weighted according to trailing 12 month dividend levels. Price index levels are set to 100 at the end of 2001.

Dividend Indices

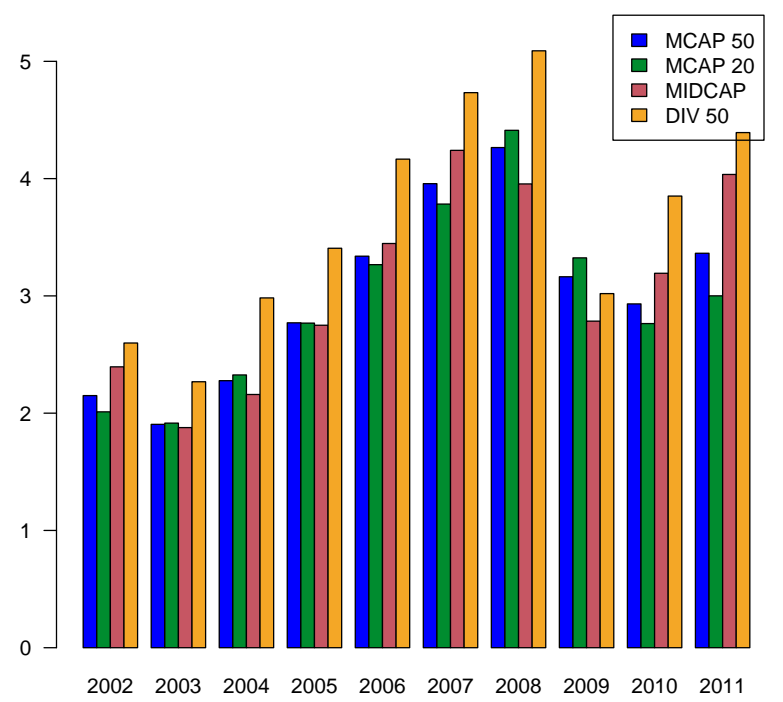

Figure 2: Dividend Indices This figure illustrates dividend index levels using four different index construction rules. Blue bars represent the reference index which matches the Euro Stoxx 50 dividend point index, green bars represent a large-cap index comprising the 20 largest stocks, red bars represent an index comprising the 20 smallest stocks of the Euro Stoxx 50 universe and orange bars represent a fundamental index weighted according to trailing 12 month dividend levels. 


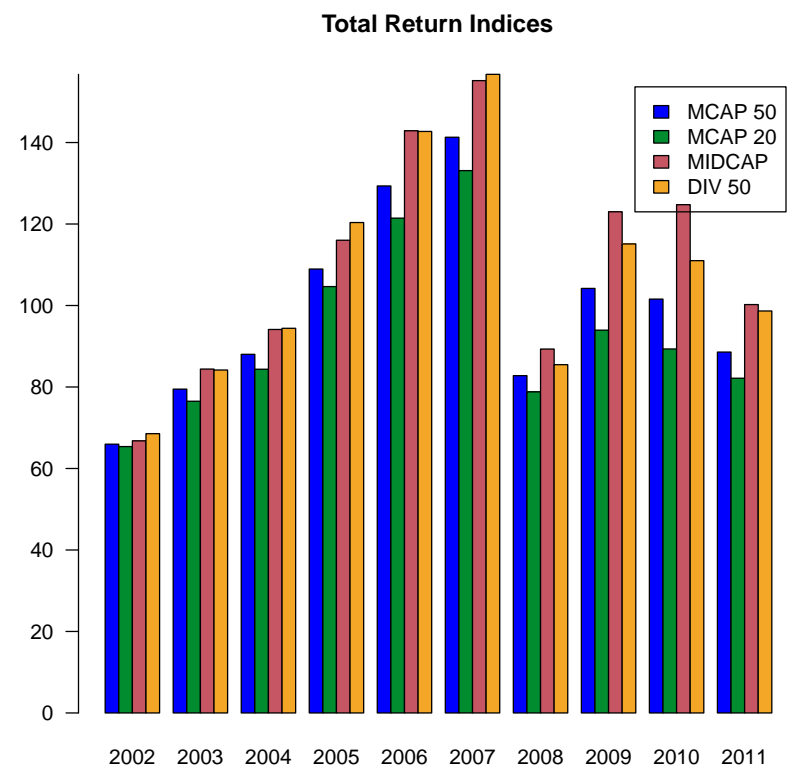

Figure 3: Total Return Indices This figure illustrates total return index levels using four different index construction rules. Blue bars represent the reference index which matches the Euro Stoxx 50, green bars represent a large-cap index comprising the 20 largest stocks, red bars represent an index comprising the 20 smallest stocks of the Euro Stoxx 50 universe and orange bars represent a fundamental index weighted according to trailing 12 month dividend levels.

It is interesting to see that the mid-cap index (smallest 20 stocks of Euro Stoxx 50 universe) performs best over the sample period from 2002 to 2011. The fundamentally weighted index, however, outperforms the reference index and the large-cap 20 index in terms of prices. For dividend indices fundamental weighting works best, followed by the mid-cap index, the reference index and the large-cap 20 index. Overall (in total return terms) the mid-cap index slightly outperforms the fundamental index. The reference index and the large-cap index perform worst. These results seem to suggest that avoiding the very large-cap stocks enhances an investor's total return. This might be due to price-to-dividend ratios of the large-cap stocks, which are too high to be fundamentally justified. We will turn to this point in more detail in the simulation setup in section 4 . Weighting the index according to dividends seems especially valuable for the dividend index. In sum, dividends appear to work well as a weighting criterion for price indices and even more so for dividend indices.

Table 6 provides annual mean returns, volatilities and modified Sharpe ratios ${ }^{19}$. Furthermore, the total return is split up into an annual price contribution and a dividend contribution. Analyzing this table reveals that the dividend contribution of the fundamentally weighted index is highest, emphasizing that higher dividends are an important factor in the

\footnotetext{
${ }^{19}$ The modified Sharpe ratio is calculated as $\frac{\text { mean }}{\text { standard deviation }}$.
} 


\begin{tabular}{|c|c|c|c|c|}
\hline & MCAP 50 & MCAP 20 & MIDCAP & DIV 50 \\
\hline \multicolumn{5}{|l|}{ Total Return } \\
\hline Mean & 0.0181 & 0.0078 & 0.0376 & 0.0339 \\
\hline St.dev. & 0.2407 & 0.2270 & 0.2700 & 0.2613 \\
\hline Mod.Sharpe & 0.0752 & 0.0344 & 0.1361 & 0.1297 \\
\hline \multicolumn{5}{|c|}{ Price Contribution } \\
\hline Mean & -0.0172 & -0.0292 & 0.0043 & -0.0067 \\
\hline St.dev. & 0.2388 & 0.2248 & 0.2689 & 0.2637 \\
\hline \multicolumn{5}{|c|}{ Dividend Contribution } \\
\hline Mean & 0.0353 & 0.0370 & 0.0325 & 0.0406 \\
\hline St.dev. & 0.0077 & 0.0093 & 0.0055 & 0.0087 \\
\hline
\end{tabular}

Table 6: Annual Performance Statistics This table provides mean returns, volatilities and modified Sharpe ratios for the total return indices as well as means and standard deviations of the price- and dividend contributions. The data range is 2002 to 2011 .

success of fundamental indices. ${ }^{20}$

\subsection{Overall Results and Limitations of the Case Study}

In interpreting the empirical analysis one has to take into account the number of events and thus data points. While it might be possible to use another equity index with richer data availability, the Euro Stoxx 50 dividend index offers the advantage of being the most liquid one in terms of dividend trading volumes, and the only major equity index that has a market for listed derivatives on both, prices and dividends. Thus, it makes sense to take the Euro Stoxx 50 as an empirical example despite limited data availability. ${ }^{21}$ As a consequence, we consider the empirical analysis of the Euro Stoxx 50 as a relevant case study that guides our further investigations (which we perform as a simulation study) presented in the following sections.

The following findings from the case study are interesting and relevant despite the limited data sample: Empirically the effects of index composition changes are economically small on the index level. This is in contrast to studies like Ranaldo and Haeberle (2008) or Cai and

\footnotetext{
${ }^{20}$ The difference in total returns of the fundamental index and the reference index is not statistically significant in our sample.

${ }^{21}$ It is a major task for a less exclusive index to create a clean sample of stock prices and dividends, for all companies that were a member of the index at least at some point in time; obtain correct adjustment factors for every corporate action of a member company; gather the exact conversion factors to combine the time series of merged or acquired companies and adjust the divisors of all passive portfolios launched after an index composition change accordingly. The study that comes closest to this task is Siegel and Schwartz (2006), who look into the very long-term effects of rebalancing the S\&P 500. This study does not look into the corresponding effects for the dividend index, though.
} 
Houge (2008), which find effects that seem to be very large in magnitude. We find the same sign for the price effect as Ranaldo and Haeberle (2008), however. On the basis of the assumption that an index composition change has no information content for investors and due to the fact that fundamental proxy variables provide no clear prediction for significant changes in future dividend payouts, it seems plausible that effects are economically small. Moreover, index composition changes tend to be more positive for price indices than for dividend indices. We further show that single stock effects (which we analyze by using pairwise comparisons) do not directly feed into the effects on the index level, as index replacements cause a reweighting of the whole set of member companies, which can have offsetting effects. Furthermore, we contradict common wisdom of sell-side analysts by showing that empirically dividend indices do not exhibit a systematic bias due to index recompositions. We also show that the discrepancy between the price index and the passive price portfolios in terms of risk-adjusted returns is in part taken up by size and value factors. Using the sample of our case study, we find that a fundamental index generates Sharpe ratios superior to market capitalization weighted indices and has a higher dividend contribution. While due to sample size these Sharpe ratio differentials are not statistically significant, they confirm earlier studies though.

\section{Simulation Approach}

Since the aim of this paper is to provide more general insight into the consequences of index composition changes and index reweighting methodologies, we need a model that allows us to evaluate index composition effects in absence of sample specific noise, and to determine important key variables affecting long-term performance differences between various index methodologies. We achieve this by implementing a simulation study for both price and dividend indices, calibrated to realistic capital market parameters. Consistent with the literature, the universe of stocks is calibrated to exhibit momentum and mean reverison. We then apply various index methodologies, index sizes and rebalancing frequencies, and compare price and dividend performance differences, to shed more light on the reasons and dynamics of the effects resulting from index reweightings. Moreover, we do not have to deal with the influence of complex corporate actions of member companies (stock splits, rights issues etc.) like in section 3, rather we can solely focus on the index dynamics caused by two sources: stocks getting replaced in the index and reweightings within the set of member companies. We are able to more easily reveal the relevant effects, by implementing extreme variants of composing the indices, namely choosing index members once and never change the composition again (so weights within the index fluctuate only with performance dispersion) as one extreme case, and rebalancing the index every period as the other extreme. Similar 
to the empirical case study we investigate whether index composition changes lead to systematic performance differences between rebalanced and non-rebalanced price and dividend indices. In contrast to the case study, we evaluate performance differences over ten years (as compared to three years). Thus, our results are of practical relevance for long-term investors. In addition to comparing market capitalization weighted indices with different rebalancing frequencies, we implement price and dividend indices fundamentally weighted by the level of dividends paid, similar to Arnott, Hsu, and Moore (2005), which enables us to compare the performance of market capitalization weighted indices to fundamentally weighted indices in presence of momentum and mean reversion. Finally, we show consequences of different index methodologies for the number of index replacements occuring, and the average priceto-dividend $(\mathrm{PD})$ ratio of the indices. A simulation study can be suited to investigate the effects mentioned and to illustrate sensitivities to the parameters used in the study. Due to the large number of relevant variables and parameters as well as their interconnections, a simulation study is preferable over a highly complex analytical model that would require numerical solution anyway.

Our general strategy is as follows. We start by setting up a universe of $N=300$ exchange traded companies for which we simulate 30 years of monthly data for both dividends and the price-to-dividend ratio. From these simulated data we calculate market capitalizations

and are thus able to construct a number of distinct market cap weighted indices, applying different rebalancing rules. In addition, we establish fundamentally weighted indices from the simulated dividends. For all index composition rules, we are able to investigate price indices as well as dividend indices over time. Finally, we analyze the sensitivity of the resulting indices with respect to index size and to the choice of parameter values describing the momentum and mean reversion dynamics of the stochastic process for the price-to-dividend ratio.

\subsection{Stochastic Processes for Dividends and Prices}

We decompose stock prices into dividends and price-to-dividend ratios, which we model separately and calibrate using dividend and price data from Euro Stoxx 50 index members. To describe their respective dynamics, we ignore general market movements, using excess returns for prices and dividend growth adjusted by average dividend growth of the market. Consider, for example, two market capitalization weighted stock indices which differ according to the number of companies included, e.g. the first index includes the 20 largest companies while the second index includes 50 stocks. If all stock prices in the market increase by $10 \%$, the same companies will remain index members and maintain their weights unchanged, so both indices will increase by $10 \%$. It is only when there is idiosyncratic variation in stock prices, 
that the two indices might perform differently. Therefore, we will focus on the idiosyncratic component only, by modeling dividends and price-to-dividend ratios such that the crosssectional average does not exhibit a systematic drift over time.

In period $t=1$, we simulate starting values for the cross-section of dividends from a lognormal distribution with parameters $\mu_{d}=20$ and $\sigma_{d}=1$. We draw the values for aggregate dividends of each company (in contrast to dividends per share). For the cross-sectional annualized price-to-dividend ratio in period $t=1$, we draw the values from a lognormal distribution with parameters $\mu_{p d}=3.6$ and $\sigma_{p d}=0.35$. The parameters are chosen to broadly match observed cross-sectional dividend and price-to-dividend ratio distributions. ${ }^{22}$

With respect to the dynamics of dividends, we simulate for each company a time path of dividends $d_{i, t}$ as

$$
d_{i, t+1}=d_{i, t} \cdot e^{\gamma_{i, t}}
$$

We define the fundamental value of dividends as the level of dividends that would yield a $\mathrm{PD}$ ratio equal to the fundamental $\mathrm{PD}$ ratio, using last period's price. Therefore,

$$
d_{i, t}^{*}=\frac{P_{i, t-1}}{P D^{*}}=\frac{d_{i, t-1} \cdot P D_{i, t-1}}{P D^{*}}
$$

We assume partial adjustment towards the fundamental dividend level:

$$
\gamma_{i, t}=\left(1-\delta_{d}\right) \cdot\left(\ln d_{i, t}^{*}-\ln d_{i, t-1}\right)+\eta_{i, t}
$$

where the noise term is specified as

$$
\eta_{i, t} \sim \mathrm{N}\left(-\frac{1}{2} \sigma_{\eta}^{2}, \sigma_{\eta}^{2}\right)
$$

To obtain an estimate of the parameter $\delta_{d}$ for the base scenario, we perform a panel regression on the annual dividend growth of all companies that have been a member of the Euro Stoxx 50 index at least at one point in time during 2001 and 2011. The parameter $\delta_{d}$ measures the degree of mean reversion towards the fundamental value, with $\delta_{d}$ closer to one meaning slower mean reversion. In the simulation, we assume monthly payment of dividends and therefore adjust the mean reversion parameter to a monthly value, by using the equivalence $\left(1-\delta_{d, \text { monthly }}\right)=\left(1-\delta_{d, \text { annual }}\right)^{1 / 12}$. The variance of the noise component $\eta_{i, t}$ is set equal to $\sigma_{\eta}^{2}$ for all companies, and its mean is chosen such that dividends do not exhibit a

\footnotetext{
${ }^{22}$ We use European stocks to calibrate these numbers. In the actual simulations, we convert the annual price-to-dividend ratio into monthly values.
} 
drift over time. We assume the noise terms to be cross-sectionally uncorrelated. Note that we do not include a monthly autoregressive component as we have only annual dividend data for estimation of dividend growth.

In contrast to the relatively simple dynamics for dividends, we allow for both mean reversion and momentum in the time series of price-to-dividend ratios. In the definiton of the stochastic process, we closely follow Balvers, Wu, and Gilliland (2000) and Balvers and $\mathrm{Wu}$ (2006), setting

$$
\begin{gathered}
P D_{i, t}=P D_{i, t-1} \cdot e^{\lambda_{i, t}} \\
\lambda_{i, t}=\left(1-\delta_{p d}\right) \cdot\left(\ln P D^{*}-\ln P D_{i, t-1}\right)+\rho \cdot \lambda_{i, t-1}+\epsilon_{i, t} \\
\epsilon_{i, t} \sim \mathrm{N}\left(-\frac{1}{2} \sigma_{\epsilon}^{2}, \sigma_{\epsilon}^{2}\right)
\end{gathered}
$$

The monthly percentage change in the price-to-dividend ratio is therefore determined by three components. First, mean reversion, with values of $\delta_{p d}$ between 0 (immediate mean reversion) and 1 (no mean reversion), gives the speed of the adjustment towards the fundamental value $P D^{*}$. The fundamental value is chosen such that it is consistent with the cross-sectional average of price-to-dividend ratios in the initial period, and we assume that $P D^{*}$ is constant both over time and cross-sectionally. Second, the momentum parameter $\rho$ allows for continuation of a trend from the previous period. Setting $\rho=0$ eliminates momentum. Third, a normally distributed noise term with variance $\sigma_{\epsilon}^{2}$ adds randomness to the price-to-dividend ratio in each period. $\epsilon_{i, t}$ is uncorrelated cross-sectionally and over time and also independent from $\eta_{i, t}$.

For the base scenario of our simulation approach, we estimate both mean reversion $\delta_{p d}$ and momentum $\rho$ from monthly data on price-to-dividend ratios of the companies that have been a member of the Euro Stoxx 50 index at least at one point in time during 2001 and 2011. To obtain monthly frequency for the price-to-dividend ratio, we use the monthly price data from Bloomberg and assume dividends to remain constant over a calendar year.

Finally, for each company, the monthly stock price is calculated from dividends and price-to-dividend ratios as $P_{i, t}=d_{i, t} \cdot P D_{i, t}$. As $d_{i, t}$ represent aggregate dividends, $P_{i, t}$ can be interpreted as market capitalization. 


\subsection{Construction of Indices}

We distinguish indices along three dimensions. First, we construct both price indices and dividend indices. Second, we distinguish indices according to whether the composition of index members varies over time or remains fixed. Third, we analyze market capitalization weighted indices and fundamentally weighted indices, where dividends serve as index inclusion and weighting criterion for the latter.

\subsubsection{Price Indices}

To compute the weights of individual stocks in a market capitalization weighted index with regular rebalancing $P I_{t}^{M C ; r e b a l}$, we sort companies each month according to their market capitalization. For large-cap indices, only the $N_{1}$ largest stocks are selected for index inclusion, while for the mid-cap index, the $N_{L}$ largest and $N_{S}$ smallest stocks are excluded and only the $N-N_{L}-N_{S}$ medium range stocks are selected for index inclusion. Each point in time, the fraction of a stock's market capitalization within the total market capitalization of all selected stocks gives the monthly weight $w_{i, t}^{M C ; r e b a l}$. Stocks not included in the index receive a weight of 0 .

An investor who wishes to track this index $P I_{t}^{M C ; r e b a l}$ will have to sell stocks that drop out of the index and buy those which are freshly included. Even ignoring transaction cost, it is not clear ex ante wether this strategy will outperform a passive buy-and-hold portfolio. We therefore construct an alternative buy-and-hold index $P I_{t}^{M C ; b h}$, where the index members remain unchanged subsequent to the initial construction period, $t^{*}$. Note, however, that even in a buy-and-hold portfolio, the relative weight of an individual stock will fluctuate with the performance of its stock price relative to the aggregate portfolio value. The weight $w_{i, t}^{M C ; b h}$ of a stock in the buy-and-hold index is therefore again calculated as the fraction of a stock's market capitalization within the total market capitalization of all selected stocks, however in contrast to the rebalanced index here the selected stocks remain unchanged over time.

One potential disadvantage of market cap weighted indices is that in case a stock is overvalued, the price and hence market capitalization for this stock will be higher than economically justified and the stocks will accordingly be overweighted in the index. Both the investment industry and recent academic literature, e.g. Arnott, Hsu, and Moore (2005), have discussed the possibility of assigning index weights according to company fundamentals. We therefore construct another alternative index, $P I_{t}^{F ; r e b a l}$, where the $N_{1}$ largest stocks with respect to the aggregate dividends paid are included (in contrast to size measured by market capitalization). An index of medium sized companies will exclude the $N_{L}$ stocks 
with the highest and the $N_{S}$ stocks with the lowest aggregate dividends paid, resulting in $N-N_{L}-N_{S}$ medium range dividend paying stocks. To obtain the weight $w_{i, t}^{F \text {;rebal }}$ of an individual share in this index, we calculate the fraction of the dividends paid by a company within the total amount of dividends paid by all index members.

All price indices are set equal to 100 in the first period: $P I_{1}^{M C ; r e b a l}=P I_{1}^{M C ; b h}=$ $P I_{1}^{F ; r e b a l}=100$. For each index, the subsequent index performance is the weighted average of individual stock performances: $R_{t}^{\text {type }}=\sum_{i=1}^{N} w_{i, t-1}^{\text {type }} \cdot\left(\frac{P_{i, t}}{P_{i, t-1}}-1\right)$, where type stands for $M C$; rebal, $M C ; b h$, and $F$; rebal. From performance, we calculate the index values in the subsequent periods: $P I_{t}^{\text {type }}=P I_{t-1}^{\text {type }} \cdot R_{t}^{\text {type }}$.

\subsubsection{Dividend Indices}

While it is straightforward to calculate price index changes as the weighted average of index member stock price changes, one additional step is needed for dividend indices. This is because pure price movements of a stock (driven by a change in the price-to-dividend ratio) do not translate into dividend changes. In order to calculate dividend indices consistent with price indices (in the sense that the underlying stock portfolio is identical for the dividend index and the corresponding price index), we therefore have to back out the number of shares $n_{i, t}^{\text {type }}=\frac{P I_{i, t}^{t y p e} \cdot w_{i, t}^{\text {type }}}{P_{i, t}}$ from weights and prices for all index types. Finally, the dividend indices are obtained as $D I_{t}^{\text {type }}=\sum_{i=1}^{N} n_{i, t}^{\text {type }} \cdot d_{i, t}$.

Dividend indices are not set equal to 100 in the first period, but represent the amount of monthly dividends paid that corresponds to the same portfolio of stocks that is also represented in the price index. Our construction therefore follows market standards, expect for the fact that we do not aggregate dividends over a year. In our setup, it is not necessary to aggregate dividends over the year because the stochastic process for dividends in our model does not exhibit seasonal patterns and the dividends are paid with the same frequency as price information is available (monthly). ${ }^{23}$

\subsection{Index Characteristics}

For price indices $P I_{t}^{\text {type }}$ and dividend indices $D I_{t}^{\text {type }}$, we calculate the percentage change $R_{t^{*}, t}^{P I, t y p e}$ and $R_{t^{*}, t}^{D I, \text { type }}$ of the index values at annual frequency, from a base period chosen to be

\footnotetext{
${ }^{23}$ To calculate an annualized dividend yield in our setup, the ratio of the dividend index to the price index has to be multiplied by 12 .
} 
the end of year $20\left(t^{*}=240\right) .{ }^{24}$ To assess the relative performance of alternative index composition rules, we calculate the price index differences $\Delta_{t^{*}, t}^{P I, r e b a l-b h}=R_{t^{*}, t}^{P I, M C ; r e b a l}-R_{t^{*}, t}^{P I, M C ; b h}$ and $\Delta_{t^{*}, t}^{P I, \text { rebal }-F}=R_{t^{*}, t}^{P I, M C ; r e b a l}-R_{t^{*}, t}^{P I, F ; r e b a l}$. We also calculate the dividend index differences $\Delta_{t^{*}, t}^{D I, \text { rebal-bh}}=R_{t^{*}, t}^{D I, M C ; \text { rebal }}-R_{t^{*}, t}^{D I, M C ; b h}$ and $\Delta_{t^{*}, t}^{D I, \text { rebal-F}}=R_{t^{*}, t}^{D I, M C ; r e b a l}-R_{t^{*}, t}^{D I, F ; \text { rebal }}$. These differences can be interpreted as pairwise comparisons of the standard case (a market cap weighted index with rebalancing) with one of two alternatives: a market cap weighted buyand-hold index, and a fundamentally weighted index with rebalancing.

In order to better understand where performance differences originate from, we also calculate the annualized price-to-dividend ratios of indices, and the relevant differences $\Delta_{t}^{P D, r e b a l-b h}$ and $\Delta_{t}^{P D, \text { rebal-F}}$. Furthermore, at each point in time $t$, we calculate for each relevant index type the number of index replacements, $n c_{t}^{M C ; r e b a l}$, and $n c_{t}^{F ; r e b a l}$, as a measure for the extent of variability in index composition. The number of index member replacements is equal to 0 for the buy-and-hold index.

\subsection{Choice of Parameters}

Table 7 summarizes the choice of parameters held constant for all variants of the simulations. We simulate paths for 300 stocks in order to allow for a sufficient number of small stocks that potentially can increase in size and be selected for an index. The number of periods simulated is 360 months, out of which the first 240 months are not analyzed with respect to index characteristics but serve as a buffer period to avoid any influence from the choice of the starting values. The monthly standard deviation for the random component of dividends is chosen to be $3 \%$, and the random component for price-to-dividend ratio is set $4 \%$, reflecting the observation that valuations fluctuate more than dividends. These numbers are in a similar range as those in Cochrane (2005).

\footnotetext{
${ }^{24}$ The choice of the base period is guided by the goal to avoid large impacts from the choice of the cross-sectional distribution of starting values for dividends and price-to-dividend ratios. Our results are not sensitive to the actual choice of $t^{*}$.
} 


\begin{tabular}{lrl}
\hline variable & value & description \\
\hline$N$ & 300 & number of companies \\
$T$ & 360 & number of periods \\
$t^{*}$ & 240 & period of first index calculation \\
$\mu_{d}$ & 20 & cross-sectional mean of log dividends $(t=1)$ \\
$\sigma_{d}$ & 1 & cross-sectional standard deviation of log dividends $(t=1)$ \\
$\mu_{p d}$ & 3.60 & cross-sectional mean of log PD ratio $(t=1)$ \\
$\sigma_{p d}$ & 0.35 & cross-sectional standard deviation of log PD ratio $(t=1)$ \\
$\sigma_{\eta}$ & 0.03 & monthly standard deviation dividend noise \\
$\sigma_{\epsilon}$ & 0.04 & monthly standard deviation PD ratio noise \\
\hline
\end{tabular}

Table 7: Parameter Values. This table reports the values for those parameters not varied across simulations.

\begin{tabular}{ll}
\hline variable & $\begin{array}{l}\text { description } \\
\text { values }\end{array}$ \\
\hline$\delta_{p d}$ & price-to-dividend ratio stickiness $(1-$ mean reversion $)$ \\
& $0.9622-\mathbf{0 . 9 6 9 4}-0.9809-0.9885-0.9918-0.9942-0.9962-0.9971$ \\
& dividend stickiness $(1-$ mean reversion $)$ \\
& $0.9679-\mathbf{0 . 9 7 4 0}-0.9818-0.9902-0.9930-0.9951-0.9967-0.9976$ \\
& $0.9727-0.9779-0.9862-0.9917-0.9941-0.9958-0.9972-0.9980$ \\
& momentum \\
& $0-\mathbf{0 . 0 0 8 0}-0.05$ \\
& number of companies included in large-cap index \\
& $20-50-100$ \\
$N_{1}$ & number of large resp. small companies excluded from mid cap index \\
& 50,100 \\
\hline
\end{tabular}

Table 8: Parameter Values. This table reports the values for those parameters varied across simulations for sensitivity analyses. Bold values indicate the base scenario obtained from calibration on data from Euro Stoxx 50 member companies. The values of $\delta_{d}$ in the first row are chosen such that the half-life of dividend mean reversion is always larger by the same extent as in the base scenario (18 percent), in the second row of the difference in the speed of adjustment is doubled.

Table 8 shows the choices of parameter values for mean reversion, momentum, and index size investigated. Stickiness of price-to-dividend ratios is measured by $\delta_{p d}$, or equivalently $\left(1-\delta_{p d}\right)$ the degree of mean reversion. Large values of $\delta_{p d}$ mean less mean reversion, with an extreme value of 1 being consistent with a random walk. The other extreme would be full adjustment within one period, given by a value of $\delta_{p d}=0$. The parameter $\rho$ measures momentum in the sense that a fraction $\rho$ of the previous period's change in the PD ratio is carried forward into the next period. We investigate monthly values between 0 (no momentum) and $5 \%$. 
From these parameter values, we select a base scenario with values $\delta_{\text {pd,base }}=0.9694$, $\delta_{d, \text { base }}=0.9740$ and $\rho_{\text {base }}=0.008$, where the parameter values are calibrated to Euro Stoxx data. The half-life corresponding to a value of $\delta_{p d, b a s e}=0.9694$ is around 2 years. In addition, we select an alternative scenario that exhibits less mean reversion $\left(\delta_{\text {pd,alter }}=0.9962\right.$, corresponding to a half-life of 15 years) and higher momentum of $\rho_{\text {alter }}=0.05$. Moreover, the difference between $\delta_{p d}$ and $\delta_{d}$ is doubled in terms of half-life.

We also distinguish indices according to the number and type of companies included. With this perspective, we select three large-cap indices and one mid-cap index. The cut-off values for the number of companies included in large-cap indices is given by the parameter $N_{1}$. We investigate three cases: an extremely exclusive index with only 20 stocks, an index alike the Eurostoxx 50, and one index comprising 100 stocks. For the mid-cap index investigated, we choose a number $N_{L}=50$ to cut off the 50 largest companies and a number $N_{S}=100$ to exclude the 100 smallest companies, leaving 150 mid-sized companies.

\section{Results}

The left chart in Figure 4 illustrates the performance differences $\Delta_{t^{*}, t}^{P I, r e b a l-b h}$ and $\Delta_{t^{*}, t}^{D I, \text { rebal-bh }}$ for a large-cap and a mid cap-index over ten years. It is interesting that for both, prices and dividends, rebalancing lowers the performance of the large-cap index using the parameters of the base scenario. Consistent with the results in section 3.2.2, underperformance is more pronounced for the dividend index. Results for the mid-cap indices are almost a mirror image of the large-cap indices. Rebalancing is positive for mid-cap indices and this is even more true for dividends. According to Panel rebal-bh, Base Case in Table 9 the average difference in the large-cap price indices, over 1000 simulation runs, is a statistically significant $0.8 \%$ over ten years (cumulative), and $2.9 \%$ for the corresponding dividend indices. The right chart in Figure 4 shows the same performance comparisons using the alternative parameters for the capital market dynamics, where both prices and dividends are more persistent $\left(\delta_{p d}=0.9962\right.$ and $\delta_{d}=0.9967$, meaning less mean reversion) but price-to-dividend ratios exhibit more momentum $(\rho=0.05)$. While there is only a tiny difference in the relative price performance, the difference in the dividend indices is much larger (with $5.6 \%$ for the large-cap index). In this scenario, stocks bought into the large-cap index at somewhat overvalued prices tend to remain overvalued over longer periods and even continue their price trend due to momentum. Over ten years, there is almost no difference in the price level of the rebalanced indices as compared to the buy-and-hold strategy. However, rebalancing appears to have adverse consequences for large-cap dividend indices since dividend streams tend to be bought at more expensive valuations than they are sold. This suggests that frequent index composition 
changes (stemming from volatility in the PD ratios) lower the relative performance of the rebalanced dividend index. For detailed results and statistical significance for all years see Table 10 and Table 11 in the appendix.
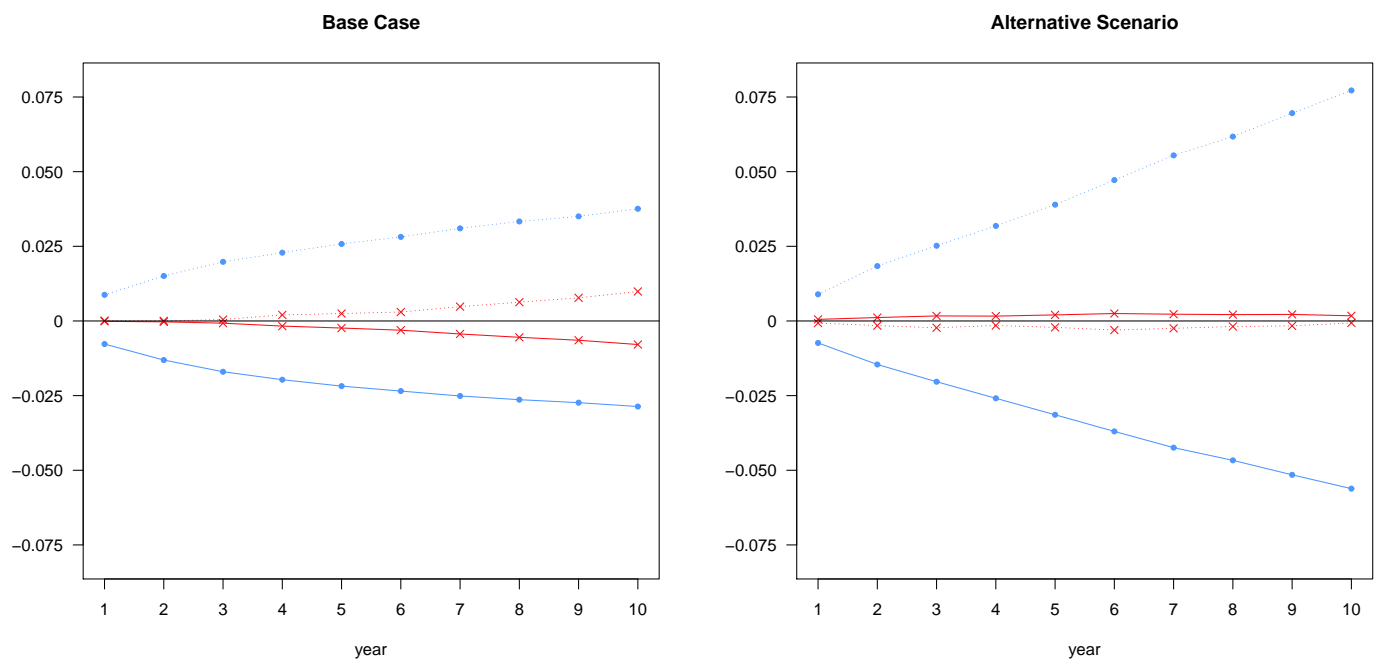

Figure 4: Rebalancing versus Buy-and-hold. This figure illustrates the simulation results for two sets of parameters over 10 years. For both prices (points denoted by x, red lines) and dividends (points denoted by o, blue lines), we compare market cap weighted indices with periodical rebalancing minus buy-and-hold. Solid lines are for large cap indices comprising 50 stocks, dashed lines for the mid-cap indices. Subfigure 1 (base scenario) is based on a mean reversion parameter of 0.9694 and momentum 0.008 for PD ratios, and a mean reversion parameter of 0.9740 for dividends. Subfigure 2 (alternative scenario) is based on mean reversion of 0.9962 and momentum of 0.05 for PD ratios and mean reversion of 0.9972 for dividends.

These observations are consistent with mean reversion being the driving force behind the index dynamics, as price-to-dividend ratios converge to their fundamental values faster than dividends. Temporarily overvalued stocks (high price-to-dividend ratios) tend to enter the large-cap index and are assigned increasing weights, whereas the index tends to sell undervalued stocks as the latter ones have smaller market capitalization. This is the opposite of what a value investor is expected to do. Frequent rebalancing execerbates this negative value bias. For the dividend indices, the difference is even worse. While for the price index, stocks bought at overvalued prices remain overvalued for some time as mean reversion kicks in only slowly (therefore mitigating the effect of buying high), for dividend indices, rebalancing means buying a stream of dividends at high prices. This same stream of dividends might be sold later at an undervalued price when the PD ratio is (maybe temporarily) low and the stock is no longer eligible for the large-cap index. The fact that the mid-cap index is a mirror image of the large-cap index can be explained by the tendency that the undervalued stocks sold by the large-cap index are bought by the mid-cap index. Since price adjustments to the fundamental value take some time but dividends bought at a price different from the fair value lead to immediate effects, it is consistent that the mid-cap dividend index benefits 
more than the mid-cap price index from regular rebalancing.

Figure 5 illustrates the relative merits of fundamental indexation by reporting $\Delta_{t^{*}, t}^{P I, r e b a l-F}$ and $\Delta_{t^{*}, t}^{D I, \text { rebal }-F}$ over time, for the basis and the alternative scenario. Market capitalization weighted indices underperform fundamentally weighted indices. The performance difference is larger for large-cap indices than for mid-cap indices (1.9\% versus $0.6 \%$ cumulative over ten years) in the base scenario. There is little difference between price and dividend indices in the base case, leading to the conclusion that fundamentally weighted indices dominate market cap weighting for both, dividends and prices under realistic capital market dynamics. While the magnitude of the price difference is smaller compared to the effect of rebalancing described above, it seems to be very robust as can be seen from the right hand chart, which shows the alterantive scenario, where the patterns are the same but slightly more pronounced in magnitude. Fundamental mid-cap indices also tend to perform better than market-cap weighted mid-cap indices, although the difference is much smaller than for large-cap indices. Effects look similar for price and dividend indices again.

As the fundamental index screens for dividend levels, stocks eligible for the fundamental index tend to have PD ratios close to the cross-sectional average, whereas stocks that qualify for the large-cap market capitalization index tend to have above average PD ratios (and still slightly above average PD ratios for the mid-cap market capitalization index). Above average PD ratios will mean revert over time. Mean reversion comes partly from dividend growth, but also from price adjustments. In contrast to the market-cap weighted index, the fundamental index has no systematic tendency to include overvalued stocks, and therefore outperforms. For dividends, buying average PD stocks is superior to buying high PD stocks, as one gets the same stream of dividends cheaper. These results provide evidence that longhorizon investors like endowment funds or sovereign wealth funds could benefit by indexing fundamentally their stock portfolios. ${ }^{25}$ While there are investment products available mirroring such fundamental index strategies, there are no investment vehicles such as listed index dividend derivatives referenced to fundamentally weighted underlyings. However, as there exist dividend derivatives on single stocks, investors can invest in a basket of single stock dividend derivatives and weight the basket by fundamental criteria (such as dividend levels). ${ }^{26}$ The results over all ten years including statistical significance are again provided in the appendix, Tables 12 and 13.

\footnotetext{
${ }^{25}$ Note, however, that it is not an equilibrium solution for all investors as markets have to clear.

${ }^{26}$ See for instance http://www.eurexchange.com/exchange-en/products/did/edf/ for a list of underlyings for single stock dividend derivatives listed on the Eurex.
} 

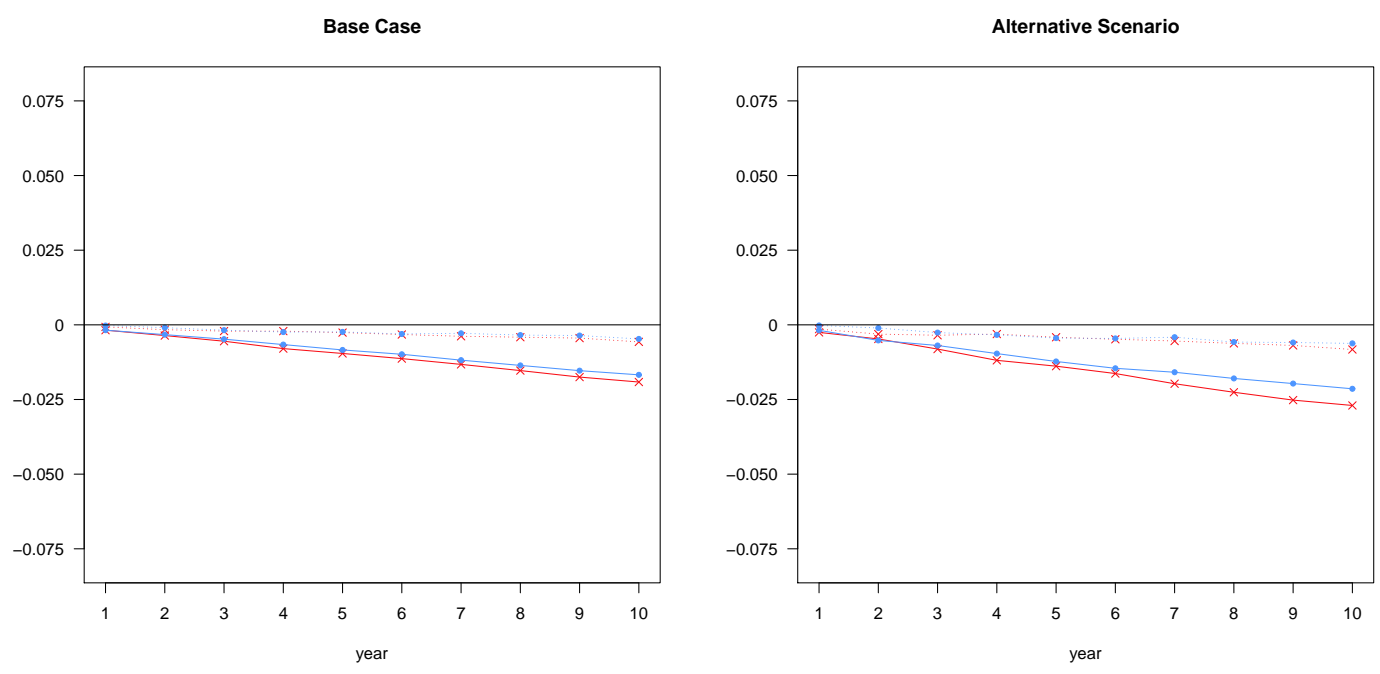

Figure 5: Market cap versus Fundamental Weights. This figure illustrates the simulation results for two sets of parameters over 10 years. For both prices (points denoted by x, red lines) and dividends (points denoted by o, blue lines), we compare market cap weighted indices minus fundamentally weighted indices, both with periodical rebalancing. Solid lines are for large-cap indices comprising 50 stocks, dashed lines for the mid-cap indices. Subfigure 1 (base scenario) is based on a mean reversion parameter of 0.9694 and momentum 0.008 for PD ratios, and a mean reversion parameter of 0.9740 for dividends. Subfigure 2 (alternative scenario) is based on mean reversion of 0.9962 and momentum of 0.05 for PD ratios and mean reversion of 0.9972 for dividends.

The following set of charts show sensitivities of the performance differentials to key parameters. Figure 6 shows sensitivities of relative index performance to different capital market dynamics for rebalanced market capitalization weighted indices. The different charts vary the index size (three large-cap indices with different numbers of components and a mid-cap index). The $\mathrm{x}$-axis varies the mean reversion coefficient of the PD ratio. The three different lines represent differences in momentum (solid and dashed) and the speed of mean reversion of dividends relative to mean reversion of the PD ratio (dotted). A first interesting observation is that for large-cap indices, performance dispersion is more pronounced, the more exclusive an index is (largest effects are in the top left chart, which represents an index comprising 20 stocks). This is consistent with the empirical findings of Ranaldo and Haeberle (2008). Turning to the mid-cap index in the bottom right chart, effects flip signs. Increasing momentum to $5 \%$ has almost no effect, with the exception of a small outperformance of the rebalanced large-cap indices when mean reversion is very slow. In contrast to the small effects of momentum, the degree of mean reversion considerably changes the observed patterns as differences in the price indices shrink and differences in the dividend indices increase. Note that the x-axis shows the values for $\delta_{p d}$, with increasing $\delta_{p d}$ representing slower mean reversion. The adjustment of dividends towards fundamental value, $\delta_{d}$, is changed proportionally (for the corresponding parameter values see Table 8). Doubling the speed differential of mean reversion (dotted lines) leads to more pronounced underperformance of rebalanced large-cap indices, especially when mean reversion is fast. 

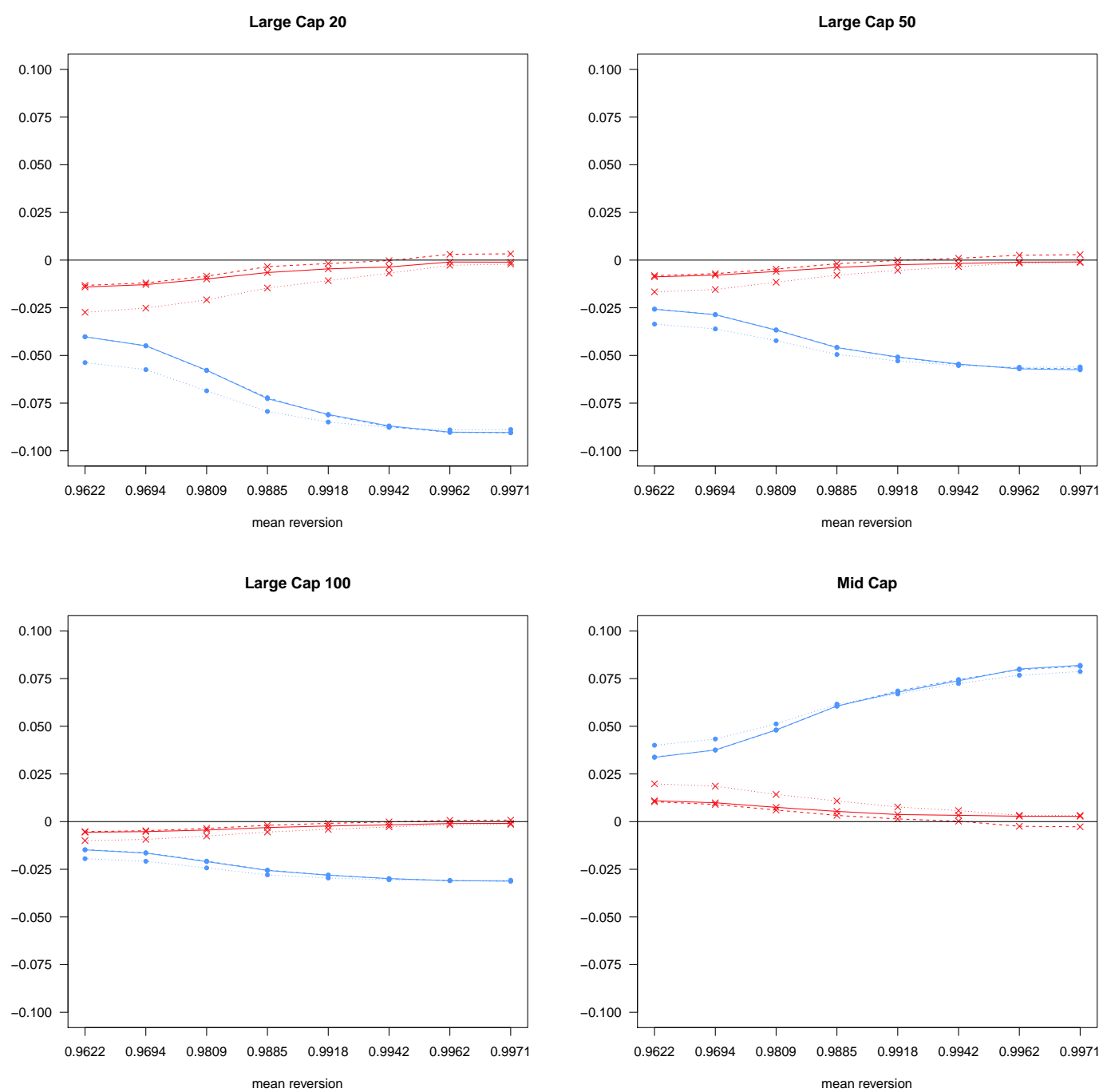

Figure 6: Rebalancing versus Buy-and-hold - Sensitivities. This figure illustrates sensitivities of the simulation results to various parameters for market cap weighted indices with periodical rebalancing minus buy-and-hold. Points denoted by $\mathrm{x}$ (red lines) represent price index differences, while points denoted by o (blue lines) represent dividend index differences. For all subfigures, the $\mathrm{x}$-axis varies the mean reversion coefficient, and the $\mathrm{y}$-axis shows the performance difference. The line style shows the momentum coefficient (solid - momentum coefficient of 0.008, dashed - momentum coefficient of 0.05) and an alternative specification for the difference between $\delta_{p d}$ and $\delta_{d}$ (dotted - difference in speed of adjustment is doubled in terms of half-life). Subfigure 1 plots results for a large cap index comprising 20 stocks, subfigure 2 a large cap index comprising 50 stocks, subfigure 3 is for a large cap index comprising 100 stocks, and subfigure 4 is for a mid cap index.

Again, the intuition of these patterns is that overvalued stocks are more likely to be included in large-cap indices at rebalancing dates. Slow mean reversion does little harm to the price index as overvalued stocks remain overvalued for longer time periods, and possibly are also sold at overvalued prices when they drop out of the index later. However, due to high PD ratios of these stocks (i.e. low dividend yield), the corresponding dividend index underperforms relative to a buy-and-hold portfolio. Mean reversion means that above average $\mathrm{PD}$ ratio stocks enter the index when there is rebalancing, but will converge to average $\mathrm{PD}$ ratios afterwards. The less those above average $\mathrm{PD}$ ratio stocks in the large-cap indices 
tend to mean revert, the better (less bad) is a high rebalancing frequency for prices. Only a combination of almost no mean reversion and relatively strong momentum can lead the rebalanced index to outperform. Slow mean reversion has adverse consequences for dividend indices, though, as even more overvalued stocks enter the rebalanced index. Again, for the mid-cap index, both the chart and its interpretation are basically a mirror image of the largecap indices. The relative performance impact of increased differences in adjustment speed between dividends and $\mathrm{PD}$ ratios $\left(\delta_{d}\right.$ versus $\left.\delta_{p d}\right)$ decreases with declining mean reversion.

Figure 7 illustrates sensitivities for the comparisons of market capitalization and fundamentally weighted indices. Again, the four charts vary index size (three large-cap and one mid-cap indices), the x-axis varies mean reversion (higher values of $\delta_{p d}$ meaning slower mean reversion), and the line types show different variants of momentum or the relative differences in the adjustment speed of PD and dividends. It is striking that outperformance of fundamental indices is very robust to capital market dynamics. For most combinations of parameter values, selecting and weighting index members according to aggregate dividends instead of market capitalization leads to outperformance of both price and dividend indices. The only exceptions with (albeit negligible) underperformance are combinations of very slow mean reversion and relatively high momentum. The difference in the speed of adjustment is an important parameter in this case, as can be seen from comparing the solid and dotted lines. The solid line connects points with mean reversion coefficients chosen such that the half-time is approximately $18 \%$ longer for dividends than for price-to-dividends ratios as seen in the data. The dotted line doubles that difference and leads to roughly a doubling in the magnitude between market-cap weighted and fundamentally weighted index performance for all index sizes. This seems plausible as under these dynamics high price-to-dividend ratios of single stocks are to a larger extent due to overvaluation and to a smaller degree due to improved future dividend growth. While the outperformance of fundamental indices appears modest at first sight in our setup, it is attractive because it seems to survive (and in many cases even increase) when parameters describing capital market dynamics are varied. 

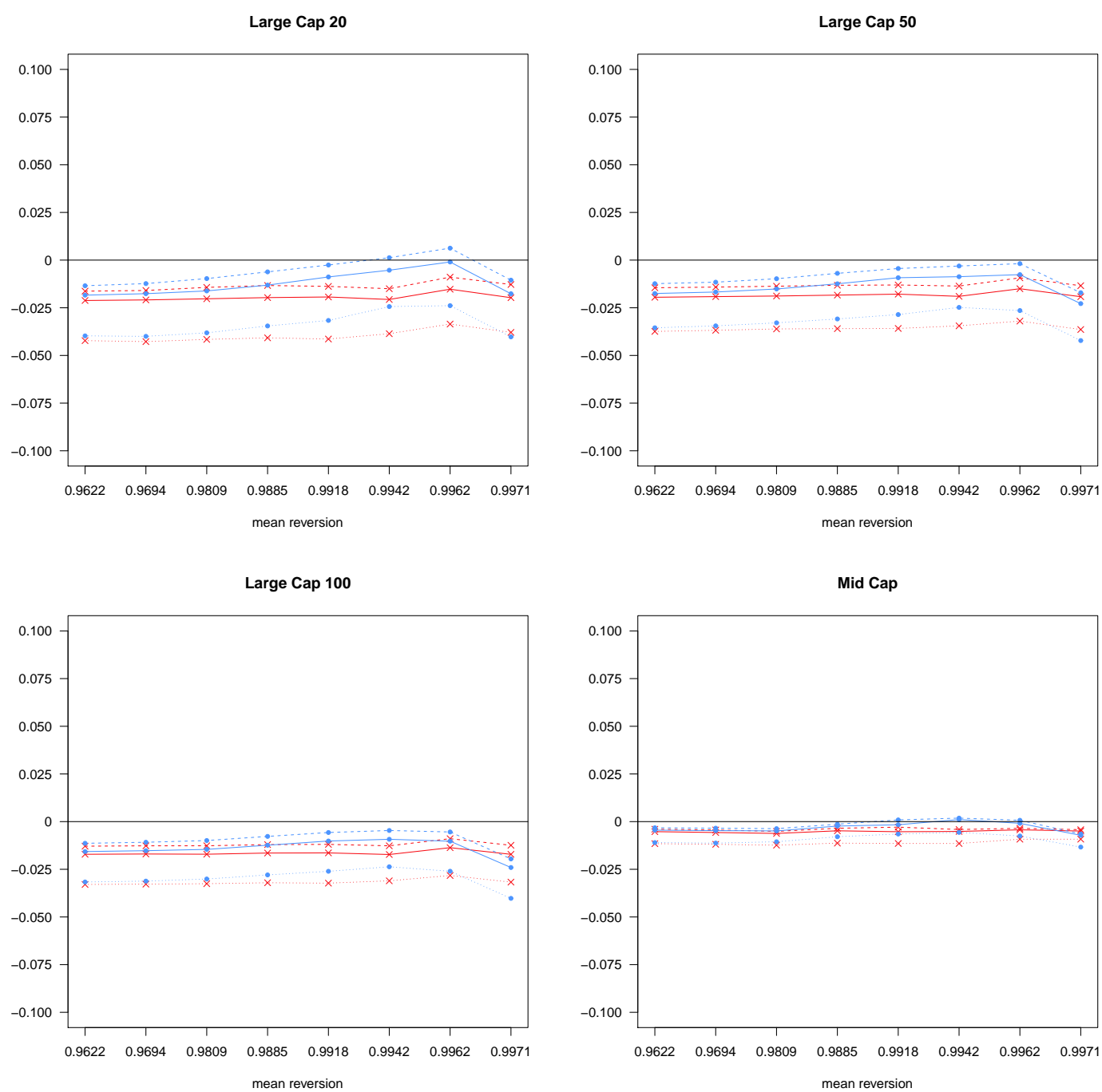

Figure 7: Market cap versus Fundamental Weights - Sensitivities. This figure illustrates sensitivities of the simulation results to various parameters for market cap weighted indices minus fundamentally weighted indices, both with periodical rebalancing. Points denoted by $\mathrm{x}$ (red lines) represent price index differences, while points denoted by o (blue lines) represent dividend index differences. For all subfigures, the x-axis varies the mean reversion coefficient, and the y-axis shows the performance difference. The line style shows the momentum coefficient (solid - momentum coefficient of 0.008, dashed - momentum coefficient of 0.05) and an alternative specification for the difference between $\delta_{p d}$ and $\delta_{d}$ (dotted - difference in speed of adjustment is doubled in terms of half-life). Subfigure 1 plots results for a large cap index comprising 20 stocks, subfigure 2 a large cap index comprising 50 stocks, subfigure 3 is for a large cap index comprising 100 stocks, and subfigure 4 is for a mid cap index.

To better understand the characteristics of various index methodologies, we now investigate changes in average PD ratios and the proportion of index member companies replaced. The four charts in Figure 8 show the difference in changes of average PD ratios of market capitalization weighted indices, with and without rebalancing. As we suspected before, rebalanced indices on average have increasing PD ratios relative to buy-and-hold portfolios, which helps to explain the underperformance of the rebalanced index. The difference in PD ratios increases when mean reversion is weaker. The degree of momentum exhibited by PD ratios and the relative speed of PD ratio and dividend mean reversion have only minor effects. 
For large-cap indices, all patterns are stronger the more exclusive an index is constructed. Again, the mid-cap index shows a mirror image as compared to the large-cap indices. The charts show that the previously described effects seem to be related to increasing PD ratios due to index rebalancing: exclusive indices weighted by market capitalization assign large weights to overvalued stocks, while the mid-cap indices tend to avoid inclusion of exactly these stocks, leading to lower average PD ratios.
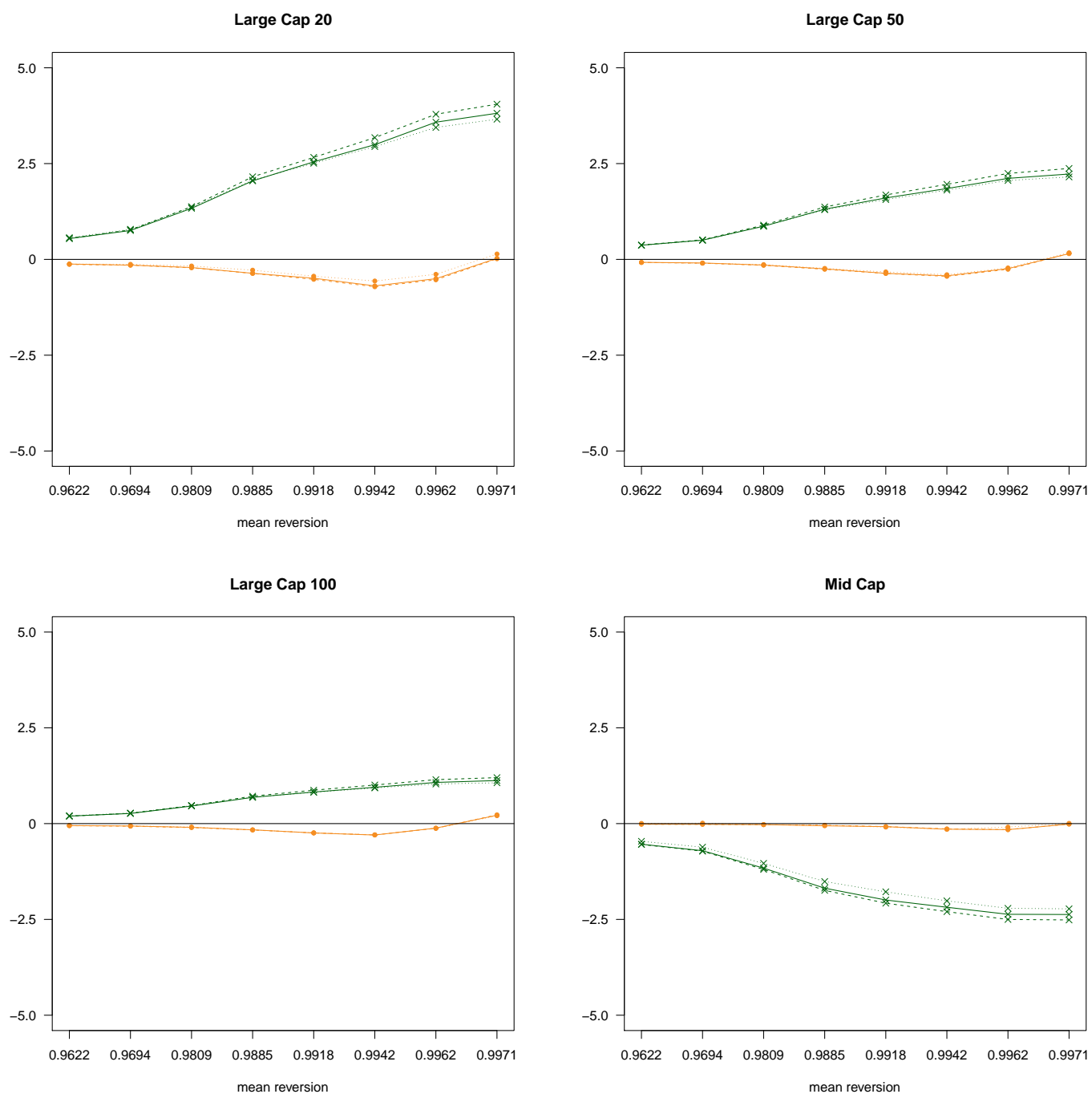

Figure 8: PD Ratio - Sensitivities. This figure illustrates sensitivities of the average price-to-dividend ratios to various parameters. Points denoted by $\mathrm{x}$ (green lines) represent changes in the difference in PD levels of market-cap weighted indices with periodical rebalancing minus buy-and-hold. Points denoted by o (orange lines) represent changes in the difference in PD levels of fundamentally weighted indices minus market-cap weighted indices. For all subfigures, the x-axis varies the mean reversion coefficient, and the y-axis shows the difference in the average price-to-dividend ratios. The line style shows the momentum coefficient (solid - momentum coefficient of 0.008, dashed - momentum coefficient of 0.05) and an alternative specification for the difference between $\delta_{p d}$ and $\delta_{d}$ (dotted - difference in speed of adjustment is doubled in terms of half-life). Subfigure 1 plots results for a large cap index comprising 20 stocks, subfigure 2 a large cap index comprising 50 stocks, subfigure 3 is for a large cap index comprising 100 stocks, and subfigure 4 is for a mid cap index.

Looking at the black lines in Figure 8, one can see that the differences in the change 
of $\mathrm{PD}$ ratios are substantially smaller in magnitude for the comparisons of market cap and fundamental indices. However, not that due to the selection criterion of the fundamental indices the level of index PD ratios is lower for the fundamental indices (which cannot be seen from the charts which illustrate the dynamics). Therefore, while fundamental indexation protects from overweighting extremely overvalued stocks, the performance advantage does not come from short term price dynamics. Due to the higher dividend yields of the fundamental indices, combining price and dividend index outperformance leads to even stronger and consistent total return outperformance compared to market-cap weighted indices.

Finally, Figure 9 exhibits sensitivities of the proportion of index replacements to the main parameters. Two results are interesting and consistent with our earlier argumentation. Firstly, for all four index sizes more index replacements occur in the market capitalization weighted indices than in the fundamentally weighted indices. This is hardly surprising as more sources of uncertainty (dividend process and PD ratio process) affect the market cap indices. Thus, the effects of buying high and selling low in the market cap indices are exacerbated through more frequent index replacements. Secondly, market-cap weighted indices appear more sensitive to momentum and mean reversion than the more inclusive indices. Higher momentum (dashed green line) and more pronounced differences in PD-ratio and dividend mean reversion (dotted green line) both lead to higher fluctuations in index members, although with very slow mean reversion the differences vanish. 
Large Cap 20

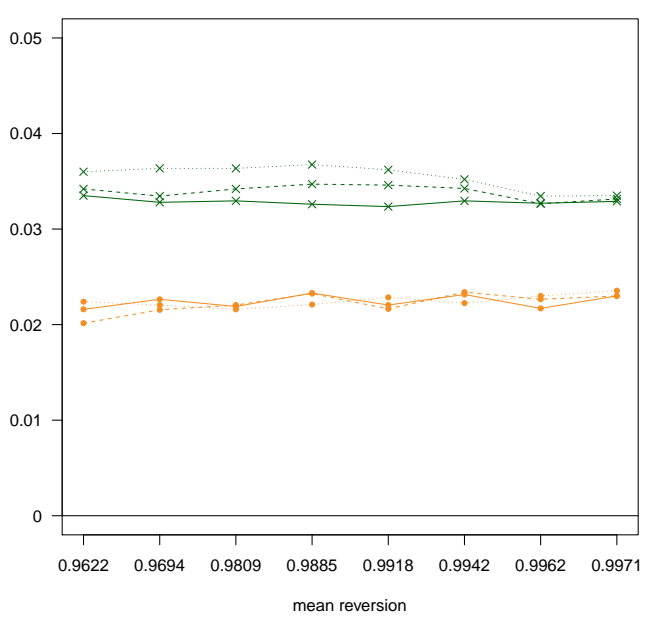

Large Cap 100

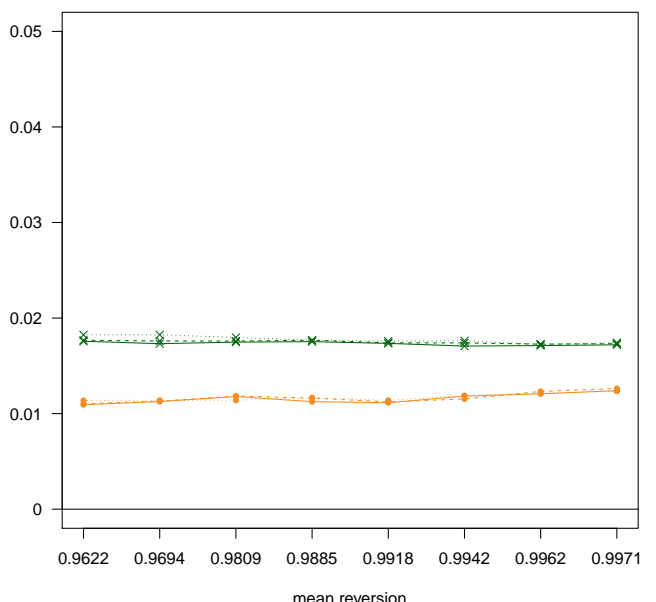

Large Cap 50

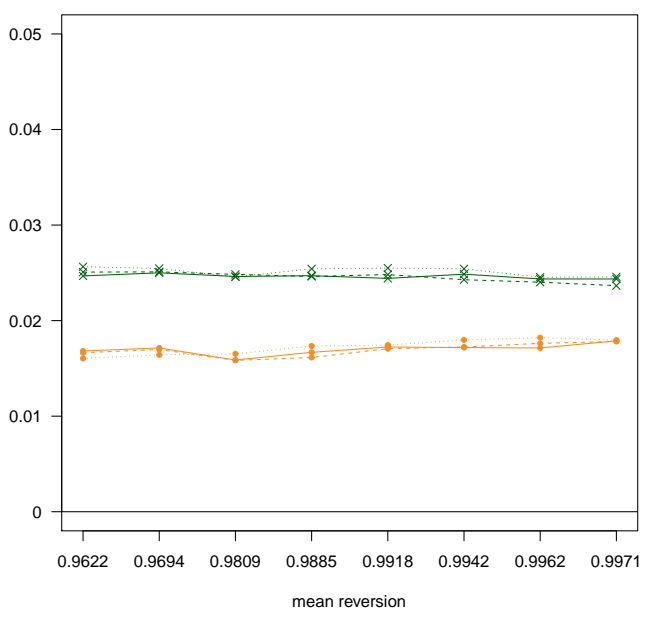

Mid Cap

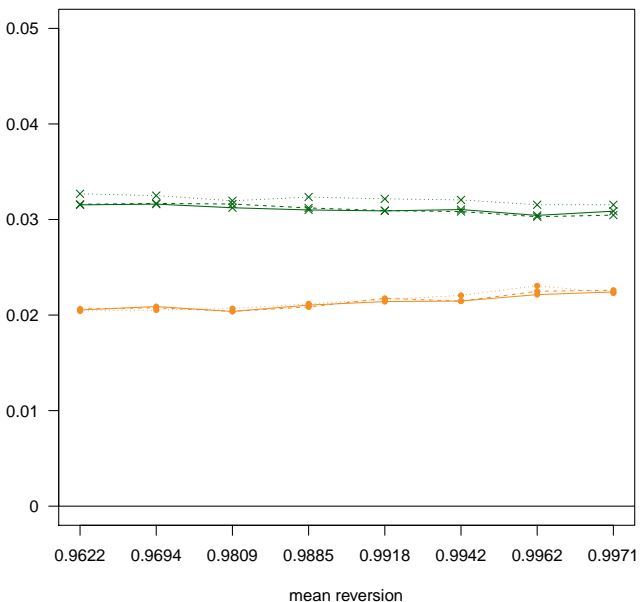

Figure 9: Number of Companies Replaced - Sensitivities. This figure shows the sensitivities of the number of companies replaced in an index to various parameters for both market cap weighted indices and fundamentally weighted indices, both with periodical rebalancing. Points denoted by $\mathrm{x}$ (green lines) represent market cap weighted indices, while points denoted by $\mathrm{o}$ (orange lines) represent fundamentally weighted indices. For all subfigures, the x-axis varies the mean reversion coefficient, and the $\mathrm{y}$-axis shows the number of companies replaced in the last period. The line style shows the momentum coefficient (solid momentum coefficient of 0.008 , dashed - momentum coefficient of 0.05) and an alternative specification for the difference between $\delta_{p d}$ and $\delta_{d}$ (dotted - difference in speed of adjustment is doubled in terms of half-life). Subfigure 1 plots results for a large cap index comprising 20 stocks, subfigure 2 a large cap index comprising 50 stocks, subfigure 3 is for a large cap index comprising 100 stocks, and subfigure 4 is for a mid cap index. 


\begin{tabular}{lccccc}
\hline & Mean & Median & Stand. Dev. & 0.1 Percentile & 0.9 Percentile \\
\hline rebal-bh, Base Case & & & & & \\
Prices Large Cap 50 & $-0.0079^{* * *}$ & -0.0078 & 0.0194 & -0.0320 & 0.0171 \\
Prices Mid Cap & $0.0099^{* * *}$ & 0.0119 & 0.0443 & -0.0493 & 0.0653 \\
Dividends Large Cap 50 & $-0.0287^{* * *}$ & -0.0279 & 0.0184 & -0.0529 & -0.0056 \\
Dividends Mid Cap & $0.0376^{* * *}$ & 0.0384 & 0.0403 & -0.0145 & 0.0875 \\
\hline rebal-bh, Alternative Scenario & & & & \\
Prices Large Cap 50 & $0.0017^{* * *}$ & 0.0014 & 0.0203 & -0.0237 & 0.0291 \\
Prices Mid Cap & -0.0007 & 0.0016 & 0.0483 & -0.0644 & 0.0631 \\
Dividends Large Cap 50 & $-0.0561^{* * *}$ & -0.0539 & 0.0248 & -0.0896 & -0.0256 \\
Dividends Mid Cap & $0.0772^{* * *}$ & 0.0742 & 0.0498 & 0.0110 & 0.1441 \\
\hline rebal-F, Base Case & & & & & 0.0067 \\
Prices Large Cap 50 & $-0.0191^{* * *}$ & -0.0192 & 0.0198 & -0.0440 & 0.0325 \\
Prices Mid Cap & $-0.0057^{* * *}$ & -0.0052 & 0.0301 & -0.0444 & 0.0104 \\
Dividends Large Cap 50 & $-0.0167^{* * *}$ & -0.0174 & 0.0212 & -0.0422 & 0.0379 \\
Dividends Mid Cap & $-0.0047^{* * *}$ & -0.0039 & 0.0337 & -0.0479 & \\
\hline rebal-F, Alternative Scenario & & & & 0.0308 \\
Prices Large Cap 50 & $-0.0270^{* * *}$ & -0.0299 & 0.0511 & -0.0876 & 0.0505 \\
Prices Mid Cap & $-0.0083^{* * *}$ & -0.0087 & 0.0452 & -0.0667 & 0.0533 \\
Dividends Large Cap 50 & $-0.0214^{* * *}$ & -0.0210 & 0.0585 & -0.0952 & -0.0949 \\
Dividends Mid Cap & $-0.0062^{* * *}$ & -0.0059 & 0.0721 & & 0.0843 \\
\hline
\end{tabular}

Table 9: Summary Statistics - Index Performance Differences. We report mean, median, standard deviation, 0.1 and 0.9 percentiles of the differences between various pairs of different index methodolgies after 10 years. All statistics are calculated on 1000 simulations runs. We show the differences for the large-cap price index, mid-cap price index, large-cap dividend index and mid-cap dividend index. In panel rebal-bh, Base Case the pairwise differences are the periodically reweighted market cap index minus a buy-and-hold index, both using the basis scenario for the price-to-dividend ratio in the simulation. Panel rebal-bh, Alternative Scenario reports the differences for the alternative scenario for the simulations. Panel rebal-F, Base Case presents the periodically reweighted market cap index minus the periodically reweighted fundamental index for the basis scenario, while Panel rebal-F, Alternative Scenario shows the difference for the alternative scenario. For means, we denote signficance at the $99 \%$ level with $* * *$.

\section{Conclusion}

This paper contributes to the literature on long-term index composition effects and extends it in several important ways. We identify key variables and parameters that affect the performance differences between various index methodologies: the magnitude of mean reversion and momentum in the price dynamics is crucial for relative index performance as well as the difference in the adjustment to the fundamental value between PD ratios and dividends. Furthermore, index size and the size bucket of stocks eligible for index membership have significant implications. Most importantly, the criteria applied for assigning weights to the index member stocks are essential. With this respect we compare market capitalization indices to both, passive non-reweighted buy-and-hold portfolios, and to fundamentally weighted indices. 
What is more, we are the first to investigate index composition effects for both, price and dividend indices, using one consistent methodology. This paper looks into the underlying economics of performance dispersion on the index level analyzing average price-to-dividend ratios of the indices and the number of index replacements implied by a specific set of parameters for the capital market dynamics. We perform a robust analysis by augmenting stylized facts obatined from an empirical case study on the Euro Stoxx 50 by a stringent simulation setup.

Drawing on the results of our empirical case study, we find that performance differences between the actual Euro Stoxx 50 indices (price and dividend) and passive buy-and-hold portfolios are small in magnitude. Furthermore, rebalancing of the index tends to be more negative for dividend indices than for price indices. Hence, we can reject a common sellside analysts' claim that dividend indices exhibit systematic upward pressure from index composition over time. Since the results of performance comparisons on the index level are somewhat different to performance comparisons of single stocks entering and exiting the index, we conclude that index reweightings caused by replacements have an important effect on the relative performance of indices. This is why studies on the long-term index effects of composition changes contribute important findings in addition to the well established strand of literature on abnormal returns of single stocks subsequent to an inclusion or exclusion. Moreover, we find that loadings on size and value factors help in explaining the slight differences between the passive buy-and-hold portfolios and the actual Euro Stoxx 50 index in terms of risk-adjusted returns.

We explore the impact of applying different index construction rules to the Euro Stoxx 50 universe for the risk-return characteristics of a total return portfolio. This confirms that fundamental weighting generates higher Sharpe ratios than market capitalization weighting (except for a mid-cap index). Moreover, a fundamentally weighted portfolio provides the highest dividend contribution to the total return.

From the simulation results we see that, using calibrated values for the mean reversion and momentum parameters of the price-to-dividend process as well as mean reversion in dividens, buy-and-hold portfolios initially weighted by market capitalization outperform frequently rebalanced market capitalization indices. Looking into average price-to-dividend ratios of the relevant indices, we reveal that this outperformance is related to larger weights assigned to above average price-to-dividend ratio stocks in the rebalanced index. This affects price indices to a smaller extent than dividend indices, since dividend streams purchased at 
an overvalued price have immediate adverse effects, whereas overvalued stocks revert to the mean only in the long-run. Comparing price and dividend indices with fundamental weights tied to the level of dividends to market capitalization weighted indices shows a significant advantage of the fundamental index.

Mid-cap indices outperform large-cap indices if weights are determined by market capitalization as stocks with very high price-to-dividend ratios are practically excluded from the mid-cap index. However, this mid-cap index still underperforms a fundamental index due to the fact that it comprisises still slightly overvalued stocks, while on average stocks that are close to fair value are eligible for the fundamental index.

By varying the main parameters, which are index size, mean reversion and momentum parameters for PD ratios as well as mean reversion parameters for dividends, we analyze sensitivities of the performace differences with respect to capital market dynamics. This reveals that mean reversion dominates momentum in terms of long-term impacts on the performance of indices. In addition, less pronounced mean reversion mitigates the underperformance of the rebalanced market cap indices for prices, whereas the opposite is true for dividend indices. As far as price indices are concerned, this is intuitive as less mean reversion allows overvalued stocks to remain overvalued for longer. In contrast, for dividend indices this seems to be related to the fact that even more overvalued dividend streams are purchased in the index, which has immediate adverse consequences. Moreover, momentum is slightly positive for large-cap price indices weighted by market capitalization as it partially offsets the tendency of above average price-to-dividend ratio stocks to revert to the mean. The opposite is true for mid-cap indices. Increasing the speed-of-adjustment difference between $\mathrm{PD}$ ratios and dividends leads to higher underperformance of the rebalanced index, for both prices and dividends. This is even more true if fundamental weighting is used as a reference. Importantly, the more exclusive an index, the stronger are the consequences of variations in the relevant parameters.

In addition to contributing to the academic literature, our results have important implications for index providers, asset managers and long-term investors. For the construction of equity and dividend indices, index providers have to take active decisions on the index size, the eligible size bucket of stocks, the rebalancing frequency and the criteria applied to assign weights to the member stocks. In conjunction with the prevailing capital market dynamics, this will have significant consequences for the performance of the indices. Asset managers tracking benchmarks have to take a stance towards their expectations for the dynamics of the price-to-dividend ratios in the relevant stock universe, in order to improve the quality of their 
choice with regard to indices. For long-term investors like endowment funds, fundamentally weighting their equity portfolios with respect to the dividend level is superior to the other indexing methods investigated, independent of the capital market dynamics. That is especially true for large-cap strategies. This can be considered an active strategy as fundamental indexation is not an equlibrium solution for all market participants. Finally, investors in dividend derivatives might consider weighting a basket of single stock dividend futures (recently listed on some exchanges) by fundamental criteria instead of utilizing index dividend derivatives, where underlyings are weighted and rebalanced by market capitalization. 


\section{References}

Arnott, Robert, Jason Hsu, and Philip Moore, 2005, Fundamental Indexation, Financial Analysts Journal.

Baker, Kent (ed.), 2009, Dividends and Dividend Policy (Wiley).

Balvers, Ronald, Thomas Cosimano, and Bill McDonald, 1990, Predicting Stock Returns in an Efficient Market, Journal of Finance.

Balvers, Ronald, and Yangru Wu, 2006, Momentum and Mean Reversion across National Equity Markets, Journal of Empirical Finance.

— , and Erik Gilliland, 2000, Mean Reversion across National Stock Markets and Parametric Contrarian Investment Strategies, Journal of Finance.

Beneish, Messod, and Robert Whaley, 1996, An Anatomy of the S\&P Game: The Effects of Changing the Rules, Journal of Finance.

— , 2002, S\&P 500 Index Replacements, Journal of Portfolio Management.

Cai, Jie, 2007, What's in the News? Information Content of S\&P 500 Additions, Financial Management.

— , and Todd Houge, 2008, The Long-Term Impact from Russel 2000 Rebalancing, Financial Analysts Journal.

Choi, Seung Mo, and Hwagyun Kim, 2013, Momentum Effect as Part of a Market Equilibrium., Journal of Financial and Quantitative Analysis, forthcoming.

Chow, Tzee-man, Jason Hsu, Vitali Kalesnik, and Bryce Little, 2011, A Survey of Alternative Equity Index Strategies, Financial Analysts Journal.

Cochrane, John, 2005, Asset Pricing (Princeton University Press).

DeAngelo, Harry, Linda DeAngelo, and Douglas Skinner, 2004, Are Dividends Disappearing? Dividend Concentration and the Consolidation of Earnings, Journal of Financial Economics.

Denis, Diane, John McConnell, Alexei Ovtchinnikov, and Yun Yu, 2003, S\&P Index Additions and Earnings Expectations, The Journal of Finance.

Denis, David, and Igor Osobov, 2008, Why do Firms Pay Dividends? international Evidence on the Determinants of Dividend Policy, Journal of Financial Economics. 
Dhillon, Upinder, and Herb Johnson, 1991, Changes in the Standard and Poor's 500 List, Journal of Business.

Edmister, Robert, Steven Graham, and Wendy Pirie, 1996, Trading Cost Expectations: Evidence from S\&P 500 Index Replacement Stock Announcements, Journal of Economics and Finance.

Eije, von Henk, and William Megginson, 2008, Dividends and Share Repurchases in the European Union, Journal of Financial Economics.

Erwin, Gayle, and James Miller, 1998, The Liquidity Effects associated with Addition of a Stock to the S\&P 500 Index: Evidence from bid/ask Spreads, Financial Review.

Fama, Eugene, and Kenneth French, 1993, Common Risk Factors in the Returns on Stocks and Bonds, Journal of Financial Economics.

— , 2001, Disappearing Dividends: Changing Firm Characteristics or Lower Propensity to Pay?, Journal of Financial Economics.

Harris, Lawrence, and Eitan Gurel, 1986, Price and Volume Effects Associated with Changes in the S\&P 500 List: New Evidence for the Existence of Price Pressures, Journal of Finance.

Jain, Prem, 1987, The Effect on Stock Price from Inclusion in or Exclusion from the S\&P 500, Financial Analysts Journal.

Kappou, Konstantina, Chris Brooks, and Charles Ward, 2008, A re-examination of the index effect: Gambling on additions to and deletions from the S\&P 500's gold seal, Research in International Business and Finance.

Lynch, Anthony, and Richard Mendenhall, 1997, New Evidence on Stock Price Effects Associated with Changes in the S\&P 500 Index, Journal of Business.

Manley, Richard, and Christian Mueller-Glissmann, 2008, The Market for Dividends and Related Investment Strategies, Financial Anaylsts Journal.

Mueller, Dennis, 1972, A Life Cycle Theory of the Firm, Journal of Industrial Economics.

Plyakha, Yuliya, 2012, Much Ado about Nothing: Benchmarking Benchmarks, Working Paper.

Ranaldo, Angelo, and Rainer Haeberle, 2008, Wolf in Sheep's Clothing: The Active Investment Strategies behind Index Performance, European Financial Management. 
Schumpeter, Joseph, 1934, The Theory of Economic Development (Harvard University Press).

Shleifer, Andrei, 1986, Do Demand Curves for Stocks Slope Down?, Journal of Finance.

Siegel, Jeremy, and Jeremy Schwartz, 2006, Long-Term Returns on the Original S\&P 500 Companies, Financial Analysts Journal.

Stoxx, 2008, Euro Stoxx 50 DVP Index Launch, Discussion paper Stoxx.

- 2012a, Stoxx DVP Guide.

— 2012b, Stoxx Index Methodology Guide.

van Binsbergen, Jules, Wouter Hueskes, Ralph Koijen, and Evert B. Vrugt, 2012, Equity Yields, Journal of Financial Economics. 


\section{A Appendix}

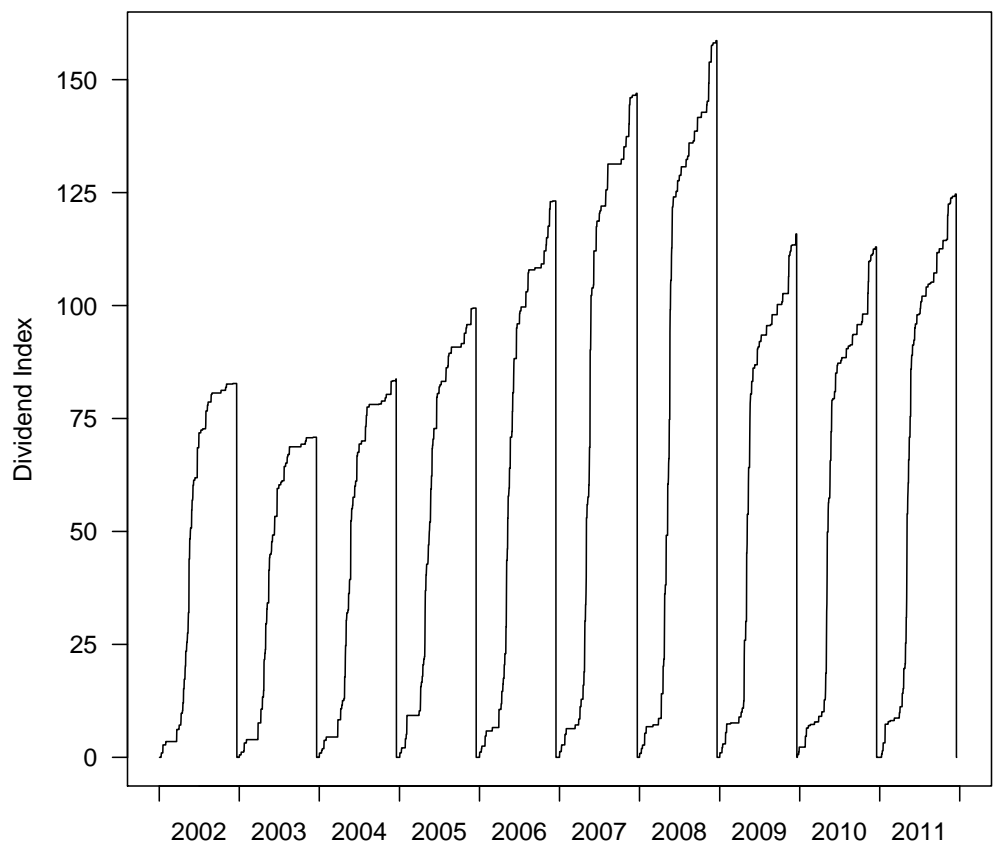

Figure 10: Dividend Index. The figure illustrates the dividend index over the sample period. The scale of the y-axis is dividend points $\left(D I_{t}\right)$ as explained in section 3.1.1. The actual Euro Stoxx 50 Dividend Index is only available starting in 2005, thus we use our own calculations for this figure. Note that dividend points accumulate over the year as member companies pay dividends. The index is then reset to zero each third friday of december. It is only meaningful to evaluate the final value of the index in december, since the shape of the accumulation during the year is a pure result of the dividend payment calender of the member companies. 


\begin{tabular}{|c|c|c|c|c|c|c|c|c|c|c|}
\hline & 1 & 2 & 3 & 4 & 5 & 6 & 7 & 8 & 9 & 10 \\
\hline \multicolumn{11}{|c|}{ Price Indices Large Cap 50} \\
\hline Mean & -0.0001 & -0.0003 & $-0.0007^{* * *}$ & $-0.0017^{* * *}$ & $-0.0024^{* * *}$ & $-0.0031^{* * *}$ & $-0.0044^{* * *}$ & $-0.0055^{* * *}$ & $-0.0065^{* * *}$ & $-0.0079^{* * *}$ \\
\hline Median & -0.0002 & -0.0003 & -0.0009 & -0.0022 & -0.0028 & -0.0035 & -0.0045 & -0.0059 & -0.0064 & -0.0078 \\
\hline Standard deviation & 0.0034 & 0.0058 & 0.0078 & 0.0095 & 0.0113 & 0.0136 & 0.0151 & 0.0169 & 0.0181 & 0.0194 \\
\hline 0.1 percentile & -0.0043 & -0.0075 & -0.0105 & -0.0133 & -0.0163 & -0.0207 & -0.0233 & -0.0266 & -0.0292 & -0.0320 \\
\hline 0.9 percentile & 0.0043 & 0.0072 & 0.0099 & 0.0110 & 0.0120 & 0.0147 & 0.0155 & 0.0160 & 0.0160 & 0.0171 \\
\hline \multicolumn{11}{|c|}{ Price Indices Mid Cap } \\
\hline Mean & 0.0001 & 0.0000 & 0.0005 & $0.0020^{* * *}$ & $0.0025^{* * *}$ & $0.0030^{* * *}$ & $0.0048^{* * *}$ & $0.0063^{* * *}$ & $0.0078^{* * *}$ & $0.0099^{* * *}$ \\
\hline Median & 0.0003 & 0.0000 & 0.0011 & 0.0036 & 0.0038 & 0.0040 & 0.0045 & 0.0069 & 0.0086 & 0.0119 \\
\hline Standard deviation & 0.0077 & 0.0129 & 0.0176 & 0.0216 & 0.0258 & 0.0304 & 0.0337 & 0.0379 & 0.0412 & 0.0443 \\
\hline 0.1 percentile & -0.0097 & -0.0168 & -0.0225 & -0.0263 & -0.0305 & -0.0368 & -0.0383 & -0.0434 & -0.0443 & -0.0493 \\
\hline 0.9 percentile & 0.0100 & 0.0164 & 0.0222 & 0.0286 & 0.0344 & 0.0412 & 0.0478 & 0.0548 & 0.0593 & 0.0653 \\
\hline \multicolumn{11}{|c|}{ Dividend Indices Large Cap 50} \\
\hline Mean & $-0.0077^{* * *}$ & $-0.0131^{* * *}$ & $-0.0170^{* * *}$ & $-0.0197^{* * *}$ & $-0.0218^{* * *}$ & $-0.0235^{* * *}$ & $-0.0251^{* * *}$ & $-0.0264^{* * *}$ & $-0.0274^{* * *}$ & $-0.0287^{* * *}$ \\
\hline Median & -0.0074 & -0.0124 & -0.0165 & -0.0193 & -0.0213 & -0.0228 & -0.0249 & -0.0262 & -0.0263 & -0.0279 \\
\hline Standard deviation & 0.0050 & 0.0064 & 0.0080 & 0.0092 & 0.0105 & 0.0122 & 0.0139 & 0.0158 & 0.0170 & 0.0184 \\
\hline 0.1 percentile & -0.0142 & -0.0211 & -0.0272 & -0.0317 & -0.0361 & -0.0392 & -0.0429 & -0.0476 & -0.0496 & -0.0529 \\
\hline 0.9 percentile & -0.0017 & -0.0056 & -0.0073 & -0.0081 & -0.0088 & -0.0085 & -0.0076 & -0.0059 & -0.0066 & -0.0056 \\
\hline \multicolumn{11}{|c|}{ Dividend Indices Mid Cap } \\
\hline Mean & $0.0088^{* * *}$ & $0.0151^{* * *}$ & $0.0198^{* * *}$ & $0.0229^{* * *}$ & $0.0258^{* * *}$ & $0.0282^{* * *}$ & $0.0310^{* * *}$ & $0.0333^{* * *}$ & $0.0350^{* * *}$ & $0.0376^{* * *}$ \\
\hline Median & 0.0085 & 0.0149 & 0.0195 & 0.0229 & 0.0252 & 0.0281 & 0.0311 & 0.0334 & 0.0347 & 0.0384 \\
\hline Standard deviation & 0.0107 & 0.0132 & 0.0166 & 0.0193 & 0.0224 & 0.0262 & 0.0298 & 0.0338 & 0.0369 & 0.0403 \\
\hline 0.1 percentile & -0.0043 & -0.0010 & -0.0015 & -0.0013 & -0.0025 & -0.0063 & -0.0070 & -0.0122 & -0.0123 & -0.0145 \\
\hline 0.9 percentile & 0.0222 & 0.0322 & 0.0406 & 0.0470 & 0.0547 & 0.0619 & 0.0691 & 0.0762 & 0.0814 & 0.0875 \\
\hline
\end{tabular}

Table 10: Rebalancing versus Buy-and-hold - Basis Scenario. Performance difference market cap reweighted index vs buy-and-hold index for the basis mean reverison $(0.9885)$ and momentum (0.02) parameters. We report mean, median, standard deviation, 0.1 and 0.9 percentiles of the differences between market cap reweighted index minus buy-and-hold index for holding periods from 1 to 10 years. In panel Prices Large Cap 50 the pairwise differences are the large cap price index index, panel Prices Mid Cap reports the differences for the mid cap index. Panel Dividends Large Cap 50 and Panel Dividends Mid Cap present the results for the dividend indices. For means, we denote signficance at the $99 \%$ level with ***, $95 \%$ with ** and $90 \%$ with *. 


\begin{tabular}{|c|c|c|c|c|c|c|c|c|c|c|}
\hline & 1 & 2 & 3 & 4 & 5 & 6 & 7 & 8 & 9 & 10 \\
\hline \multicolumn{11}{|c|}{ Price Indices Large Cap 50} \\
\hline Mean & $0.0005^{* * *}$ & $0.0012^{* * *}$ & $0.0017^{* * *}$ & $0.0016^{* * *}$ & $0.0020^{* * *}$ & $0.0025^{* * *}$ & $0.0023^{* * *}$ & $0.0021^{* * *}$ & $0.0022^{* * *}$ & $0.0017^{* * *}$ \\
\hline Median & 0.0004 & 0.0011 & 0.0013 & 0.0007 & 0.0014 & 0.0016 & 0.0014 & 0.0012 & 0.0014 & 0.0014 \\
\hline Standard deviation & 0.0035 & 0.0060 & 0.0082 & 0.0100 & 0.0118 & 0.0142 & 0.0159 & 0.0176 & 0.0187 & 0.0203 \\
\hline 0.1 percentile & -0.0036 & -0.0063 & -0.0090 & -0.0102 & -0.0119 & -0.0145 & -0.0177 & -0.0201 & -0.0209 & -0.0237 \\
\hline 0.9 percentile & 0.0050 & 0.0090 & 0.0125 & 0.0146 & 0.0170 & 0.0212 & 0.0229 & 0.0252 & 0.0264 & 0.0291 \\
\hline \multicolumn{11}{|c|}{ Price Indices Mid Cap } \\
\hline Mean & $-0.0007^{* * *}$ & $-0.0016^{* * *}$ & $-0.0023^{* * *}$ & $-0.0015^{* *}$ & $-0.0021^{* *}$ & $-0.0030^{* * *}$ & $-0.0025^{* *}$ & -0.0019 & -0.0016 & -0.0007 \\
\hline Median & -0.0004 & -0.0013 & -0.0018 & -0.0006 & -0.0008 & -0.0018 & -0.0013 & -0.0014 & 0.0002 & 0.0016 \\
\hline Standard deviation & 0.0080 & 0.0139 & 0.0190 & 0.0231 & 0.0274 & 0.0326 & 0.0366 & 0.0412 & 0.0442 & 0.0483 \\
\hline 0.1 percentile & -0.0113 & -0.0193 & -0.0260 & -0.0315 & -0.0376 & -0.0449 & -0.0506 & -0.0553 & -0.0588 & -0.0644 \\
\hline 0.9 percentile & 0.0093 & 0.0158 & 0.0228 & 0.0275 & 0.0320 & 0.0373 & 0.0439 & 0.0504 & 0.0551 & 0.0631 \\
\hline \multicolumn{11}{|c|}{ Dividend Indices Large Cap 50} \\
\hline Mean & $-0.0074^{* * *}$ & $-0.0146^{* * *}$ & $-0.0203^{* * *}$ & $-0.0259^{* * *}$ & $-0.0314^{* * *}$ & $-0.0370^{* * *}$ & $-0.0424^{* * *}$ & $-0.0467^{* * *}$ & $-0.0515^{* * *}$ & $-0.0561^{* * *}$ \\
\hline Median & -0.0073 & -0.0143 & -0.0194 & -0.0259 & -0.0310 & -0.0369 & -0.0423 & -0.0458 & -0.0508 & -0.0539 \\
\hline Standard deviation & 0.0125 & 0.0148 & 0.0167 & 0.0184 & 0.0193 & 0.0207 & 0.0223 & 0.0233 & 0.0241 & 0.0248 \\
\hline 0.1 percentile & -0.0226 & -0.0321 & -0.0410 & -0.0494 & -0.0564 & -0.0624 & -0.0699 & -0.0758 & -0.0821 & -0.0896 \\
\hline 0.9 percentile & 0.0079 & 0.0037 & -0.0006 & -0.0037 & -0.0074 & -0.0115 & -0.0146 & -0.0178 & -0.0214 & -0.0256 \\
\hline \multicolumn{11}{|c|}{ Dividend Indices Mid Cap } \\
\hline Mean & $0.0089^{* * *}$ & $0.0184^{* * *}$ & $0.0252^{* * *}$ & $0.0318^{* * *}$ & $0.0389^{* * *}$ & $0.0472^{* * *}$ & $0.0554^{* * *}$ & $0.0617^{* * *}$ & $0.0696^{* * *}$ & $0.0772^{* * *}$ \\
\hline Median & 0.0076 & 0.0181 & 0.0237 & 0.0304 & 0.0367 & 0.0453 & 0.0539 & 0.0600 & 0.0667 & 0.0742 \\
\hline Standard deviation & 0.0227 & 0.0268 & 0.0307 & 0.0346 & 0.0363 & 0.0398 & 0.0426 & 0.0450 & 0.0483 & 0.0498 \\
\hline 0.1 percentile & -0.0199 & -0.0144 & -0.0123 & -0.0114 & -0.0076 & -0.0021 & 0.0013 & 0.0068 & 0.0099 & 0.0110 \\
\hline 0.9 percentile & 0.0384 & 0.0529 & 0.0660 & 0.0751 & 0.0859 & 0.0965 & 0.1093 & 0.1209 & 0.1333 & 0.1441 \\
\hline
\end{tabular}

Table 11: Rebalancing versus Buy-and-hold - Alternative Scenario.Performance difference market cap reweighted index vs buy-and-hold index for alternative parameters of mean reversion (0.9977) and momentum (0.05). We report mean, median, standard deviation, 0.1 and 0.9 percentiles of the differences between market cap reweighted index minus buy-and-hold index for holding periods from 1 to 10 years. In panel Prices Large Cap 50 the pairwise differences are the large cap price index index, panel Prices Mid Cap reports the differences for the mid cap index. Panel Dividends Large Cap 50 and Panel Dividends Mid Cap present the results for the dividend indices. For means, we denote signficance at the $99 \%$ level with ***, $95 \%$ with ** and $90 \%$ with *. 


\begin{tabular}{|c|c|c|c|c|c|c|c|c|c|c|}
\hline & 1 & 2 & 3 & 4 & 5 & 6 & 7 & 8 & 9 & 10 \\
\hline \multicolumn{11}{|c|}{ Price Indices Large Cap 50} \\
\hline Mean & $-0.0018^{* * *}$ & $-0.0036^{* * *}$ & $-0.0055^{* * *}$ & $-0.0080^{* * *}$ & $-0.0096^{* * *}$ & $-0.0113^{* * *}$ & $-0.0132^{* * *}$ & $-0.0153^{* * *}$ & $-0.0175^{* * *}$ & $-0.0191^{* * *}$ \\
\hline Median & -0.0019 & -0.0038 & -0.0063 & -0.0082 & -0.0102 & -0.0113 & -0.0137 & -0.0149 & -0.0180 & -0.0192 \\
\hline Standard deviation & 0.0068 & 0.0096 & 0.0116 & 0.0132 & 0.0145 & 0.0158 & 0.0171 & 0.0175 & 0.0186 & 0.0198 \\
\hline 0.1 percentile & -0.0103 & -0.0158 & -0.0199 & -0.0247 & -0.0276 & -0.0309 & -0.0344 & -0.0370 & -0.0409 & -0.0440 \\
\hline 0.9 percentile & 0.0070 & 0.0083 & 0.0091 & 0.0086 & 0.0081 & 0.0087 & 0.0089 & 0.0073 & 0.0066 & 0.0067 \\
\hline \multicolumn{11}{|c|}{ Price Indices Mid Cap } \\
\hline Mean & $-0.0007^{* *}$ & $-0.0016^{* * *}$ & $-0.0021^{* * *}$ & $-0.0021^{* * *}$ & $-0.0026^{* * *}$ & $-0.0032^{* * *}$ & $-0.0038^{* * *}$ & $-0.0041^{* * *}$ & $-0.0044^{* * *}$ & $-0.0057^{* * *}$ \\
\hline Median & -0.0003 & -0.0018 & -0.0017 & -0.0018 & -0.0029 & -0.0039 & -0.0044 & -0.0046 & -0.0046 & -0.0052 \\
\hline Standard deviation & 0.0092 & 0.0130 & 0.0161 & 0.0189 & 0.0208 & 0.0227 & 0.0249 & 0.0264 & 0.0283 & 0.0301 \\
\hline 0.1 percentile & -0.0130 & -0.0187 & -0.0234 & -0.0257 & -0.0276 & -0.0313 & -0.0349 & -0.0366 & -0.0404 & -0.0444 \\
\hline 0.9 percentile & 0.0113 & 0.0154 & 0.0189 & 0.0223 & 0.0235 & 0.0263 & 0.0286 & 0.0298 & 0.0313 & 0.0325 \\
\hline \multicolumn{11}{|c|}{ Dividend Indices Large Cap 50} \\
\hline Mean & $-0.0018^{* * *}$ & $-0.0033^{* * *}$ & $-0.0048^{* * *}$ & $-0.0066^{* * *}$ & $-0.0084^{* * *}$ & $-0.0099^{* * *}$ & $-0.0118^{* * *}$ & $-0.0136^{* * *}$ & $-0.0153^{* * *}$ & $-0.0167^{* * *}$ \\
\hline Median & -0.0019 & -0.0039 & -0.0053 & -0.0081 & -0.0093 & -0.0105 & -0.0129 & -0.0144 & -0.0156 & -0.0174 \\
\hline Standard deviation & 0.0088 & 0.0119 & 0.0134 & 0.0152 & 0.0164 & 0.0176 & 0.0185 & 0.0193 & 0.0201 & 0.0212 \\
\hline 0.1 percentile & -0.0127 & -0.0174 & -0.0216 & -0.0253 & -0.0283 & -0.0313 & -0.0336 & -0.0369 & -0.0403 & -0.0422 \\
\hline 0.9 percentile & 0.0101 & 0.0119 & 0.0116 & 0.0129 & 0.0128 & 0.0120 & 0.0114 & 0.0109 & 0.0100 & 0.0104 \\
\hline \multicolumn{11}{|c|}{ Dividend Indices Mid Cap } \\
\hline Mean & -0.0002 & -0.0010 & $-0.0018^{* * *}$ & $-0.0024^{* * *}$ & $-0.0024^{* * *}$ & $-0.0031^{* * *}$ & $-0.0028^{* * *}$ & $-0.0034^{* * *}$ & $-0.0036^{* * *}$ & $-0.0047^{* * *}$ \\
\hline Median & -0.0004 & -0.0013 & -0.0013 & -0.0009 & -0.0012 & -0.0030 & -0.0029 & -0.0037 & -0.0047 & -0.0039 \\
\hline Standard deviation & 0.0145 & 0.0185 & 0.0214 & 0.0239 & 0.0251 & 0.0267 & 0.0290 & 0.0309 & 0.0316 & 0.0337 \\
\hline 0.1 percentile & -0.0183 & -0.0247 & -0.0290 & -0.0346 & -0.0354 & -0.0381 & -0.0389 & -0.0422 & -0.0443 & -0.0479 \\
\hline 0.9 percentile & 0.0178 & 0.0219 & 0.0256 & 0.0254 & 0.0288 & 0.0316 & 0.0338 & 0.0365 & 0.0378 & 0.0379 \\
\hline
\end{tabular}

Table 12: Market Cap versus Fundamental Weights - Basis Scenario. Performance difference market cap reweighted index vs fundamentally reweighted index for the basis mean reverison (0.9885) and momentum (0.02) parameters. We report mean, median, standard deviation, 0.1 and 0.9 percentiles of the differences between market cap reweighted index minus buy-and-hold index for holding periods from 1 to 10 years. In panel Prices Large Cap 50 the pairwise differences are the large cap price index index, panel Prices Mid Cap reports the differences for the mid cap index. Panel Dividends Large Cap 50 and Panel Dividends Mid Cap present the results for the dividend indices. For means, we denote signficance at the $99 \%$ level with ***, $95 \%$ with ** and $90 \%$ with *. 


\begin{tabular}{|c|c|c|c|c|c|c|c|c|c|c|}
\hline & 1 & 2 & 3 & 4 & 5 & 6 & 7 & 8 & 9 & 10 \\
\hline \multicolumn{11}{|c|}{ Price Indices Large Cap 50} \\
\hline Mean & $-0.0025^{* * *}$ & $-0.0047^{* * *}$ & $-0.0081^{* * *}$ & $-0.0119^{* * *}$ & $-0.0138^{* * *}$ & $-0.0163^{* * *}$ & $-0.0197^{* * *}$ & $-0.0226^{* * *}$ & $-0.0252^{* * *}$ & $-0.0270^{* * *}$ \\
\hline Median & -0.0028 & -0.0050 & -0.0091 & -0.0121 & -0.0140 & -0.0171 & -0.0208 & -0.0232 & -0.0265 & -0.0299 \\
\hline Standard deviation & 0.0169 & 0.0233 & 0.0281 & 0.0325 & 0.0361 & 0.0399 & 0.0429 & 0.0450 & 0.0477 & 0.0511 \\
\hline 0.1 percentile & -0.0233 & -0.0342 & -0.0431 & -0.0523 & -0.0593 & -0.0654 & -0.0738 & -0.0787 & -0.0814 & -0.0876 \\
\hline 0.9 percentile & 0.0187 & 0.0240 & 0.0272 & 0.0289 & 0.0313 & 0.0331 & 0.0357 & 0.0318 & 0.0324 & 0.0308 \\
\hline \multicolumn{11}{|c|}{ Price Indices Mid Cap } \\
\hline Mean & $-0.0014^{* * *}$ & $-0.0031^{* * *}$ & $-0.0035^{* * *}$ & $-0.0031^{* * *}$ & $-0.0042^{* * *}$ & $-0.0048^{* * *}$ & $-0.0054^{* * *}$ & $-0.0062^{* * *}$ & $-0.0069^{* * *}$ & $-0.0083^{* * *}$ \\
\hline Median & -0.0016 & -0.0032 & -0.0041 & -0.0037 & -0.0048 & -0.0052 & -0.0059 & -0.0066 & -0.0070 & -0.0087 \\
\hline Standard deviation & 0.0146 & 0.0205 & 0.0249 & 0.0293 & 0.0322 & 0.0350 & 0.0382 & 0.0409 & 0.0436 & 0.0452 \\
\hline 0.1 percentile & -0.0202 & -0.0298 & -0.0337 & -0.0391 & -0.0447 & -0.0493 & -0.0551 & -0.0619 & -0.0631 & -0.0667 \\
\hline 0.9 percentile & 0.0178 & 0.0215 & 0.0280 & 0.0341 & 0.0358 & 0.0396 & 0.0436 & 0.0445 & 0.0486 & 0.0505 \\
\hline \multicolumn{11}{|c|}{ Dividend Indices Large Cap 50} \\
\hline Mean & $-0.0018^{* *}$ & $-0.0052^{* * *}$ & $-0.0069^{* * *}$ & $-0.0096^{* * *}$ & $-0.0123^{* * *}$ & $-0.0146^{* * *}$ & $-0.0159^{* * *}$ & $-0.0179^{* * *}$ & $-0.0197^{* * *}$ & $-0.0214^{* * *}$ \\
\hline Median & -0.0018 & -0.0064 & -0.0076 & -0.0091 & -0.0133 & -0.0154 & -0.0153 & -0.0187 & -0.0195 & -0.0210 \\
\hline Standard deviation & 0.0253 & 0.0321 & 0.0380 & 0.0432 & 0.0468 & 0.0502 & 0.0525 & 0.0557 & 0.0577 & 0.0585 \\
\hline 0.1 percentile & -0.0329 & -0.0463 & -0.0545 & -0.0654 & -0.0710 & -0.0759 & -0.0801 & -0.0878 & -0.0898 & -0.0952 \\
\hline 0.9 percentile & 0.0301 & 0.0363 & 0.0414 & 0.0442 & 0.0466 & 0.0481 & 0.0521 & 0.0542 & 0.0516 & 0.0533 \\
\hline \multicolumn{11}{|c|}{ Dividend Indices Mid Cap } \\
\hline Mean & -0.0002 & -0.0011 & $-0.0026^{*}$ & $-0.0034^{* *}$ & $-0.0044^{* *}$ & $-0.0045^{* *}$ & $-0.0041^{* *}$ & $-0.0058^{* * *}$ & $-0.0059^{* * *}$ & $-0.0062^{* * *}$ \\
\hline Median & -0.0013 & -0.0012 & -0.0030 & -0.0032 & -0.0057 & -0.0036 & -0.0031 & -0.0016 & -0.0071 & -0.0059 \\
\hline Standard deviation & 0.0338 & 0.0411 & 0.0468 & 0.0530 & 0.0566 & 0.0618 & 0.0639 & 0.0678 & 0.0714 & 0.0721 \\
\hline 0.1 percentile & -0.0424 & -0.0520 & -0.0622 & -0.0690 & -0.0736 & -0.0838 & -0.0838 & -0.0929 & -0.0931 & -0.0949 \\
\hline 0.9 percentile & 0.0434 & 0.0530 & 0.0562 & 0.0608 & 0.0681 & 0.0721 & 0.0758 & 0.0784 & 0.0864 & 0.0843 \\
\hline
\end{tabular}

Table 13: Market Cap versus Fundamental Weights - Alternative Scenario. Performance difference market cap reweighted index vs fundamentally reweighted index for alternative parameters of mean reversion (0.9977) and momentum (0.05). We report mean, median, standard deviation, 0.1 and 0.9 percentiles of the differences between market cap reweighted index minus buy-and-hold index for holding periods from 1 to 10 years. In panel Prices Large Cap 50 the pairwise differences are the large cap price index index, panel Prices Mid Cap reports the differences for the mid cap index. Panel Dividends Large Cap 50 and Panel Dividends Mid Cap present the results for the dividend indices. For means, we denote signficance at the $99 \%$ level with ***, $95 \%$ with ** and $90 \%$ with *. 